\title{
Regional surface morphology of comet 67P/Churyumov-Gerasimenko from Rosetta/OSIRIS images ${ }^{\star}$
}

\author{
M. R. El-Maarry ${ }^{1}$, N. Thomas ${ }^{1}$, L. Giacomini ${ }^{2}$, M. Massironi ${ }^{2}$, M. Pajola ${ }^{3}$, R. Marschall ${ }^{1}$, A. Gracia-Berná ${ }^{1}$, \\ H. Sierks ${ }^{4}$, C. Barbieri ${ }^{5}$, P. L. Lamy ${ }^{6}$, R. Rodrigo ${ }^{7}$, H. Rickman ${ }^{8}$, D. Koschny ${ }^{9}$, H. U. Keller ${ }^{10}$, J. Agarwal ${ }^{4}$, \\ M. F. A'Hearn ${ }^{11}$, A.-T. Auger ${ }^{6}$, M. A. Barucci ${ }^{12}$, J.-L. Bertaux ${ }^{13}$, I. Bertini ${ }^{14}$, S. Besse ${ }^{9}$, D. Bodewits ${ }^{11}$, \\ G. Cremonese, ${ }^{5}$, V. Da Deppo ${ }^{15}$, B. Davidsson ${ }^{16}$, M. De Cecco $^{17}$, S. Debei ${ }^{18}$, C. Güttler ${ }^{4}$, S. Fornasier ${ }^{13}$, M. Fulle ${ }^{19}$, \\ O. Groussin ${ }^{6}$, P. J. Gutierrez ${ }^{20}$, S. F. Hviid ${ }^{21}$, W.-H. Ip ${ }^{22}$, L. Jorda ${ }^{23}$, J. Knollenberg ${ }^{21}$, G. Kovacs ${ }^{4}$, J.-R. Kramm ${ }^{4}$, \\ E. Kührt ${ }^{21}$, M. Küppers ${ }^{24}$, F. La Forgia ${ }^{5}$, L. M. Lara ${ }^{20}$, M. Lazzarin ${ }^{5}$, J. J. Lopez Moreno ${ }^{20}$, S. Marchi ${ }^{25}$, F. Marzari ${ }^{5}$, \\ H. Michalik ${ }^{26}$, G. Naletto ${ }^{27,14,15}$, N. Oklay ${ }^{4}$, A. Pommerol ${ }^{1}$, F. Preusker ${ }^{21}$, F. Scholten ${ }^{21}$, \\ C. Tubiana ${ }^{4}$, and J.-B. Vincent ${ }^{4}$ \\ (Affiliations can be found after the references)
}

Received 23 January 2015 / Accepted 12 May 2015

\section{ABSTRACT}

\begin{abstract}
Aims. The OSIRIS camera onboard the Rosetta spacecraft has been acquiring images of the comet 67P/Churyumov-Gerasimenko (67P)'s nucleus at spatial resolutions down to $\sim 0.17 \mathrm{~m} / \mathrm{px}$ ever since Aug. 2014. These images have yielded unprecedented insight into the morphological diversity of the comet's surface. This paper presents an overview of the regional morphology of comet 67P.

Methods. We used the images that were acquired at orbits $\sim 20-30 \mathrm{~km}$ from the center of the comet to distinguish different regions on the surface and introduce the basic regional nomenclature adopted by all papers in this Rosetta special feature that address the comet's morphology and surface processes. We used anaglyphs to detect subtle regional and topographical boundaries and images from close orbit ( $\sim 10 \mathrm{~km}$ from the comet's center) to investigate the fine texture of the surface.

Results. Nineteen regions have currently been defined on the nucleus based on morphological and/or structural boundaries, and they can be grouped into distinctive region types. Consolidated, fractured regions are the most common region type. Some of these regions enclose smooth units that appear to settle in gravitational sinks or topographically low areas. Both comet lobes have a significant portion of their surface covered by a dusty coating that appears to be recently placed and shows signs of mobilization by aeolian-like processes. The dusty coatings cover most of the regions on the surface but are notably absent from a couple of irregular large depressions that show sharp contacts with their surroundings and talus-like deposits in their interiors, which suggests that short-term explosive activity may play a significant role in shaping the comet's surface in addition to long-term sublimation loss. Finally, the presence of layered brittle units showing signs of mechanical failure predominantly in one of the comet's lobes can indicate a compositional heterogeneity between the two lobes.
\end{abstract}

Key words. comets: general - comets: individual: 67P/Churyumov-Gerasimenko - methods: observational

\section{Introduction}

The Rosetta spacecraft was inserted into orbit around comet 67P/Churyumov-Gerasimenko (67P) on Aug. 6, 2014. Since then, the comet's nucleus has been extensively imaged and monitored by the Optical, Spectroscopic, and Infrared Remote Imaging System (Keller et al. 2007, OSIRIS) at spatial resolutions ranging from $12 \mathrm{~m} / \mathrm{px}$ to $0.17 \mathrm{~m} / \mathrm{px}$. The OSIRIS images have shown the surface of comet $67 \mathrm{P}$ to be morphologically complex with several terrain types and numerous intricate features (Sierks et al. 2015; Thomas et al. 2015).

Here we describe the general regional morphology of comet $67 \mathrm{P}$ and introduce the nomenclature that has been assigned to well-defined regions on the surface (Fig. 1). This nomenclature is adopted by all current and upcoming papers that deal with features and processes on the surface of the nucleus. Some of the features introduced here are discussed more extensively in other papers in this Rosetta special feature. For instance, Auger et al. (2015) present a detailed geomorphological investigation

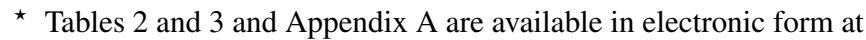
http://www . aanda.org of the Imhotep region, Pajola et al. (2015) report on the sizefrequency distribution on boulders on the surface of the comet, Pommerol et al. (2015) discuss the photometry of bright boulders, Thomas et al. (2015) investigate the dust deposits in more detail, and Keller et al. (2015) investigate the role of erosion and insolation on the surface morphology.

\section{Methods and nomenclature}

OSIRIS consists of a narrow-angle $(38.4 \times 38.7 \mathrm{mrad}$ FOV $)$ camera (NAC) designed for the mapping of the comet's surface with 12 filters covering the spectral range of $250-1000 \mathrm{~nm}$ in high spatial resolution, and a wide-angle $(198 \times 211 \mathrm{mrad}$ FOV $)$ camera (WAC), which is optimized for the gas and dust studies in the vicinity of the comet with 14 filters in the spectral range of 240-720 nm (Keller et al. 2007). In this study, we use images acquired from the time of first orbit insertion (Aug. 6, 2014) to Nov. 12, 2014, in particular those taken with the "Orange" filter (centered at approx $650 \mathrm{~nm}$ ).

The image resolutions for the NAC varied during this time period from approx $2 \mathrm{~m} / \mathrm{px}$ to $0.17 \mathrm{~m} / \mathrm{px}$, while the WAC varied 


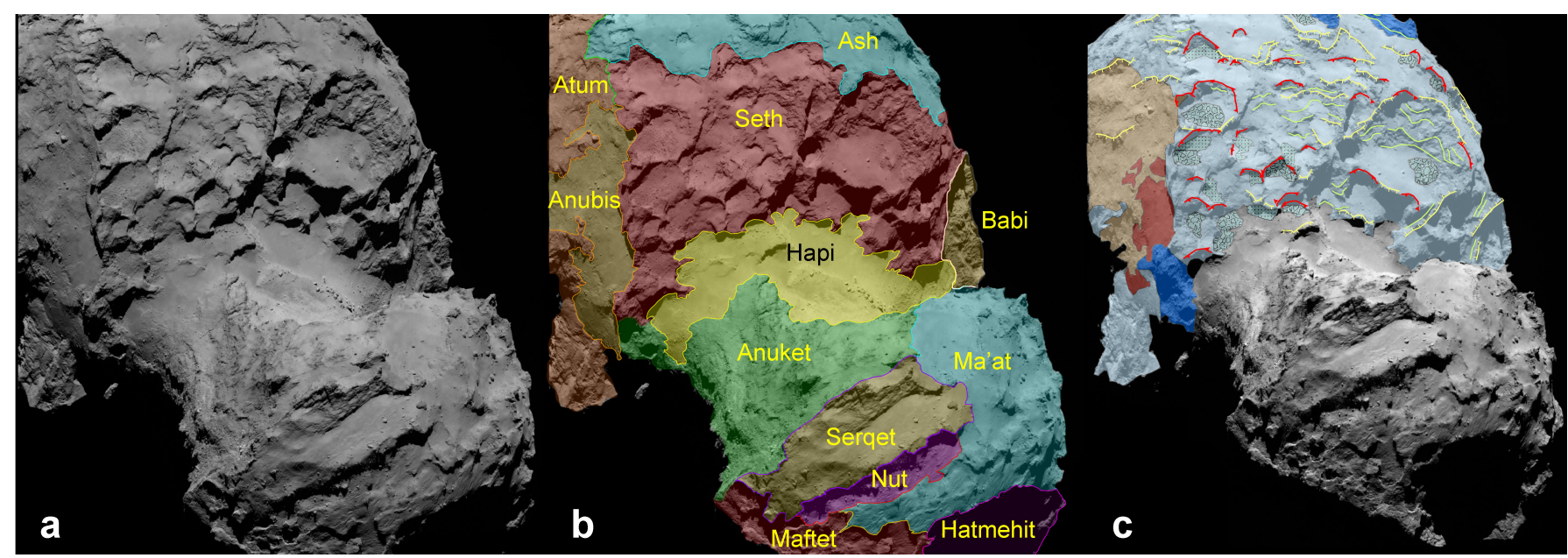

Fig. 1. a) NAC image of comet $67 \mathrm{P}$ showing many of the regions discussed in this paper. b) Same image with regional boundaries and nomenclatures added. c) NAC image showing a similar, but not identical, view of the comet with superposed geological/geomorphological units to highlight the differences between both techniques. Refer to the main text for details. For original image IDs of this figure in addition to all other figures in the paper, please refer to Table 3 .

from approx $12 \mathrm{~m} / \mathrm{px}$ to $1 \mathrm{~m} / \mathrm{px}$ depending on the distance to the nucleus (approx $120 \mathrm{~km}$-approx $10 \mathrm{~km}$ ). The NAC images were predominantly used during the early mapping phase. However, as the mapping progressed and Rosetta moved to closer orbits around the nucleus, WAC images were gradually utilized with the NAC providing extremely high spatial resolution, yet with small spatial coverage. It should be noted that a regional physiographic classification is different from a conventional geological mapping. An example of such mapping is shown in Fig. 1 to highlight the differences and will be presented in more detail in Giacomini et al. (in prep.). In geological mapping, units that display similar structural and stratigraphic position, as well as a common possible origin, are grouped into one unit irrespective of their spatial distribution or disparity of their outcrops. Moreover, in a geological map, structural elements, such as major faults and fractures, must be present, surface deposits should be distinguished, and morphological features, such as scarps, cuestas, niches and dune crests, can be reported.

In a regional classification the surface is divided into distinctive coherent regions based on clear and major morphological and/or topographical boundaries. This is essential in the case of newly discovered and small planetary bodies that lack a well-established geographical reference system in order to aid with the orientation and subsequent mapping of various features (see Thomas et al. 2012; Massironi et al. 2012, as examples of regional and geological mapping of the asteroid 21Lutetia). Nonetheless, both mapping techniques should broadly agree on major morphological and regional boundaries, and both are essential for a comprehensive morphological characterization of the surface.

Another point to note is that in our description of the units, we use certain terminology that needs to be clarified here. For instance, we use the term "consolidated material" to refer to units that appear rocky in appearance and are cohesive enough to display lineaments and fractures. The reason for using this term is that the very low estimated bulk density $\left(\sim 0.5 \mathrm{~g} / \mathrm{cm}^{3}\right)$ makes it unlikely that the surface is dominated by terrestrial-like rocks that are usually a factor of 5-10 denser (Thomas et al. 2015; Sierks et al. 2015). Also, we use the term "brittle" to refer to weakly consolidated materials showing signs of mechanical failure and gradually evolving into talus-like deposits as opposed to more competent or strongly consolidated materials. As such, this should not be confused with the mechanical term, which corresponds to materials that easily fracture rather than releasing stress in an elastic or plastic manner. "Smooth terrains" refer to units that generally appear to be composed of non-cohesive materials (although these may still be influenced by van der Waals forces) enclosed by rough consolidated units and are particularly thick enough to mask the underlying units. Finally, the term "dust coating" is used to describe materials that show signs of wide-spread mobilization, and appear to be thin enough to reveal numerous outcrops of the underlying units.

In total, 19 regions have been identified so far with more expected to be added when the currently dark parts of the surface are illuminated later in the mission (see Sect. 3). The boundaries of the different regions were defined at sharp changes in surface morphology (e.g., rough vs smooth surface) or clear morphostructural/topographical boundaries (e.g., ridges or edges of a depression). Whenever possible, anaglyphs were produced using images of similar spatial resolution and illumination geometry, as well as acceptable convergence angles. At times, the images were rotated or scaled with respect to each other in order to achieve proper co-registration. The anaglyphs were mainly used to identify and assess topographical boundaries between adjacent regions as well as changes in relief. A few examples are available in Appendix A.

Finally, in accordance with the general theme of the Rosetta mission in using ancient Egyptian names, regions were named after ancient Egyptian deities. Regions on the smaller lobe (see Sect. 3) were given female names, whereas regions on the larger lobe and the neck region inbetween were assigned male names.

\section{Regional morphology}

The nucleus of 67P comprises two lobes connected by a short "neck" region (Fig. 2). Shape models of the nucleus show that the larger lobe (hereinafter referred to as the body) has a size of about $4.1 \times 3.3 \times 1.8 \mathrm{~km}$, whereas the smaller lobe (hereinafter referred to as the head) is $2.6 \times 2.3 \times 1.8 \mathrm{~km}$ (Sierks et al. 2015). At the time of writing, the comet had not been imaged in its entirety because the obliquity of the comet's rotational axis $\left(52^{\circ}\right)$ currently puts in shadow significant parts of the comet's surface $(\sim 30 \%)$, including the southern pole. However, these areas will 
M. R. El-Maarry et al.: Regional surface morphology of comet 67P

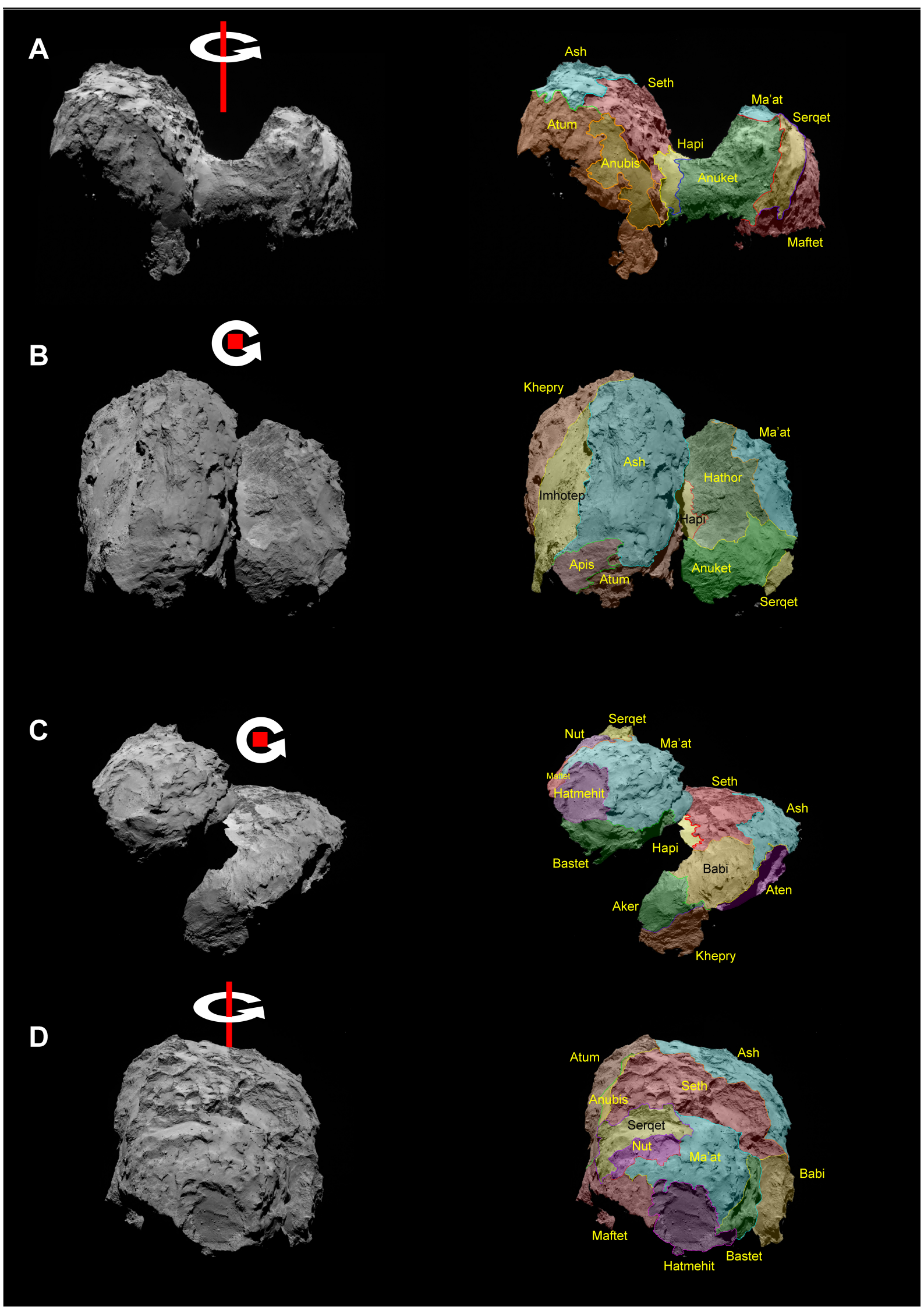

Fig. 2. Left: WAC (panel A)) and NAC images (the rest) showing the comet in different orientations. Rotation axes have been added for better orientation. In panels $\mathbf{B}$ ) and $\mathbf{C}$ ), the rotation axis is almost toward the viewer (north polar view). Right: same images with regional boundaries and nomenclature superposed. 
Table 1. Distribution of various features of interest that have been discussed in the text.

\begin{tabular}{|c|c|c|c|c|c|c|c|c|c|}
\hline Feature/Region & Active pits & $\mathrm{CM}$ & Layering & Fractures & CC/P-SM & SD & $\mathrm{D} / \mathrm{A}$ & Terraces & Lineaments \\
\hline Aker (B) & & & & $X(3 d)$ & & $\mathrm{X}$ & & & $\mathrm{X}$ \\
\hline Khepry (B) & & & & $X$ & & $X$ & & & \\
\hline Imhotep (B) & & & $\mathrm{X}$ & & $X(4 c)$ & $X^{*}(4 c)$ & & $X(4 c)$ & \\
\hline Aten (B) & & $X$ & & & & & & & \\
\hline Ash (B) & & $X$ & $\mathrm{X}$ & & & & $X^{*}(5 c)$ & $X(5 d)$ & \\
\hline Seth (B) & $X^{*}(7 d)$ & $X^{*}(7 b)$ & $X$ & $X(7 c)$ & & & $\mathrm{X}$ & $\mathrm{X}$ & $X$ \\
\hline Babi (B) & & $\mathrm{X}$ & $X(9 d)$ & & & & $X$ & & \\
\hline Apis (B) & & & & $X(11 c)$ & & & & & \\
\hline Atum (B) & & & $\mathrm{X}$ & $X$ & & & & $\mathrm{X}$ & \\
\hline Anubis (B) & & & & & & $X^{*}(14 a)$ & & & \\
\hline Hapi $(\mathrm{N})$ & & & & & & $X^{*}(15 a)$ & & & \\
\hline Hathor $(\mathrm{H})$ & & & & $X$ & & & & $X(16 b)$ & $\mathrm{X}$ \\
\hline Anuket $(\mathrm{H})$ & & & & $X$ & & & X (19d) & & \\
\hline Ma'at $(\mathrm{H})$ & $X$ & $X$ & & $X$ & & & $X^{*}(20 c)$ & & \\
\hline Serqet $(H)$ & & $\mathrm{X}$ & & $X$ & & $\mathrm{X}$ & $X(21 b)$ & & \\
\hline Nut $(\mathrm{H})$ & & & & $X$ & & & & & \\
\hline Maftet $(\mathrm{H})$ & & & & $X(22 d)$ & & & & & \\
\hline Bastet $(\mathrm{H})$ & & $X(24 b)$ & & $X(24 b)$ & & & & & $X(24 b)$ \\
\hline Hatmehit $(\mathrm{H})$ & & $X(25)$ & & $X$ & & $X(25)$ & & & \\
\hline
\end{tabular}

Notes. The presence of a given structure or feature in a region is given by marked by an " $\mathrm{X}$ ". An " $\mathrm{X}$ "” symbol corresponds to either a dominant feature in a region (e.g. dust in Ash) or the highest concentration of a specific feature (e.g., active pits in Seth). Numbers in parenthesis correspond to figures that show a particularly good example of the corresponding feature. The letters " $\mathrm{B}$ ", "N" and " $\mathrm{H}$ " next to the regions' names refers to its position on the comet on the body, neck or head, respectively. The acronyms in the header columns correspond to the following respectively: collapsing material (CM), cratered cones/Pancake-shaped mounds (CC/P-SM), smooth deposits (SD), and dust/airfall (D/A). Finally, the locations of active pits are from Vincent et al. (2015).

become illuminated in later parts of the mission, which should result in identifying new regions.

In our ensuing discussion, we list and discuss the different regions in order of their location first on the body followed by the neck and the head regions. We describe the general morphological traits of each region, its geographical context, and the location and nature of its boundaries with neighboring regions. A compilation of the distribution of a number of common or noteworthy surface features in each region is summarized in Table 1 while a summary of the regions' basic morphology and important features is given in Table 2, Finally Table 3 lists the image IDs used in this study.

\subsection{Body lobe}

\subsubsection{Khepry and Aker}

Khepry and Aker are two of the regions on 67P that have a consolidated appearance. The regions appear rough in terms of surface texture and are heavily lineated showing little or no boulders with Aker being slightly smoother in surface texture than Khepry. Both Khepry and Aker contain extremely smooth patches (50-100 m dimension) of material which are observed in local topographic lows and surrounded by rougher material (Fig. 3). In addition, Aker contains what appears to be a set of angular fractures $>200 \mathrm{~m}$ in length (Fig. 3d). The fractures appear to be associated with a sharp ridge that separates Aker from the Babi region (Sect. 3.1.6, see Figs. 3a and 6b).

Khepry appears to surround significant parts of the Imhotep region (Sect. 3.1.2) and may extend into the currently nonilluminated areas. It generally displays a sharp morphological and topographical transition with Imhotep's smooth and topographically lower terrain. Khepry is separated from Aten and Babi by sharp scarps whereas its boundary with Aker is defined by a transition to the smoother and less lineated surface textures of Aker (Fig. 3). Similarly for Aker, its extent in the non-illuminated areas is still unknown. It extends toward the neck where it gives way to Hapi's smooth terrain. The transition is marked by a sharp cliff.

\subsubsection{Imhotep}

The Imhotep region is geologically one of the most diverse regions on the nucleus (see Auger et al. 2015). It is dominated by a smooth bouldered surface (see Pajola et al. 2015) overlying rougher terrain, which appears to be enclosed in part by Khepry (Fig. 4). The smooth materials display sharp and curvilinear features (Fig. 4c) that may be indicative of terracing underneath potentially thinner sections of the smooth deposits. In fact, the enclosing consolidated materials show evidence of terracing in a few locations (Fig. 4c). One of these locations, a pronounced $650 \mathrm{~m}$-wide circular mesa is irregularly fractured in general but tends to form polygonal patterns in some places (Fig. 4d).

The smooth material thins out toward the Apis/Atum side and gives way to a terrain dominated by circular filled and unfilled structures, which are further investigated in Auger et al. (2015). Imhotep is the only region on the imaged surface with these types of structures at this time.

Imhotep borders the Khepry, Ash, and Apis regions in addition to at least one currently non-illuminated region (Figs. 4a, b). The boundary with Apis is dominated by a sharp scarp but is also texturally gradational as the rougher sections of Imhotep grade into a more consolidated one (i.e. showing less debris and collapsing materials) in Apis. The boundary with Khepry tends to be sharper in certain locations where there is a clear transition from the smooth deposits into the higher-standing and rougher textures of Khepry. Finally, the boundary with Ash is marked by a transition to a dust-covered brittle material. 
M. R. El-Maarry et al.: Regional surface morphology of comet 67P

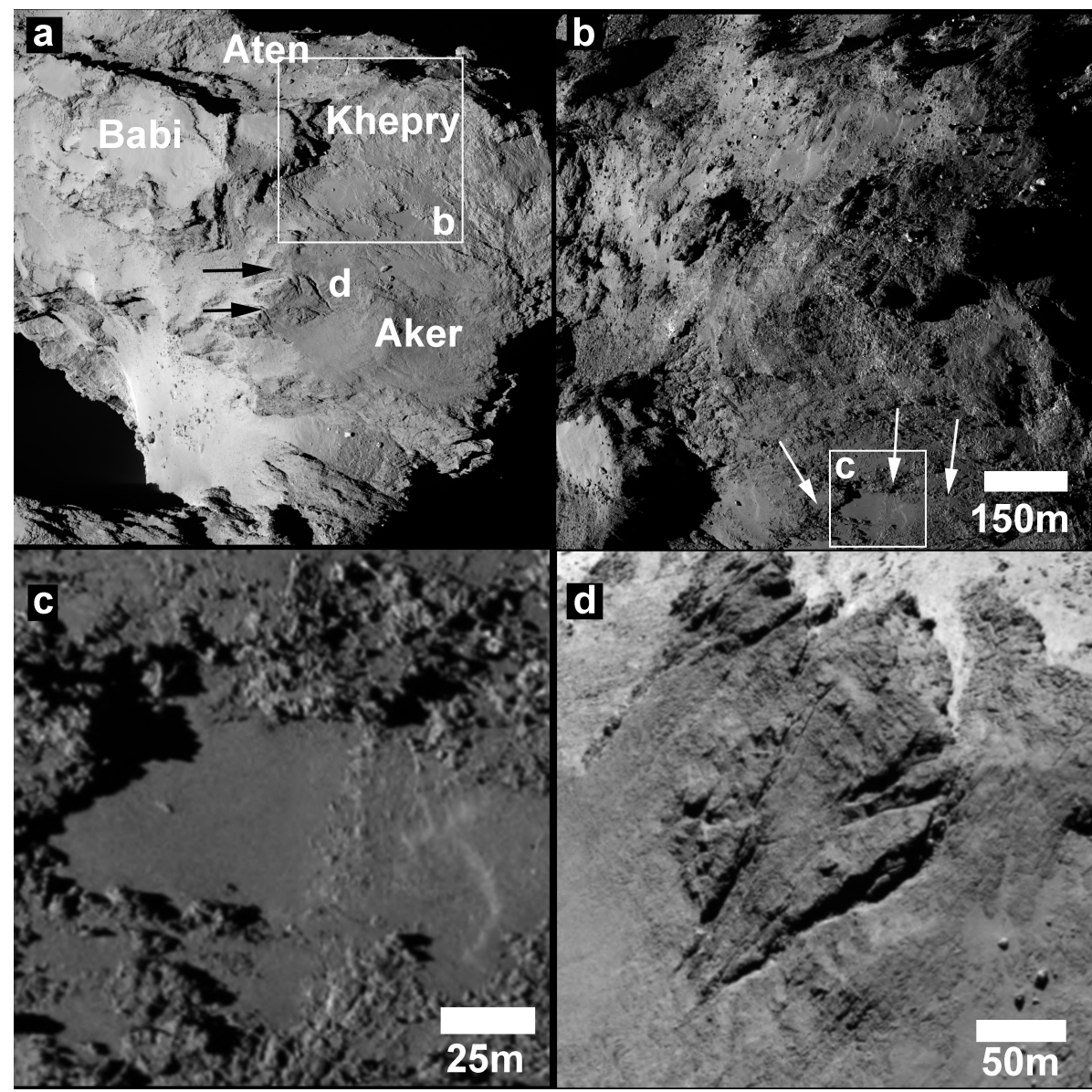

Fig. 3. a) NAC image showing the Khepry and Aker regions as well as parts of Babi and Aten. For the exact boundary between the two regions refer to Fig. 2. Note the angular fractures, which are shown as close-up in d), which are associated with the ridge separating Aker from Babi (arrows) and further highlighted in Fig. 6b. b) NAC image showing parts of the Khepry region. Note the rough surface texture and the ponding of smooth deposits in topographic lows, which is further highlighted in c). Arrows point to parts of the boundary between Khepry and Aker. c) Close-up view of same image in b) showing one of the smooth patches in Khepry. d) Cropped NAC image showing the angular fractures in Aker, which measure $\sim 200 \mathrm{~m}$ in length. The view has been rotated $\sim 90^{\circ}$ with respect to Fig. 3a for clarity.

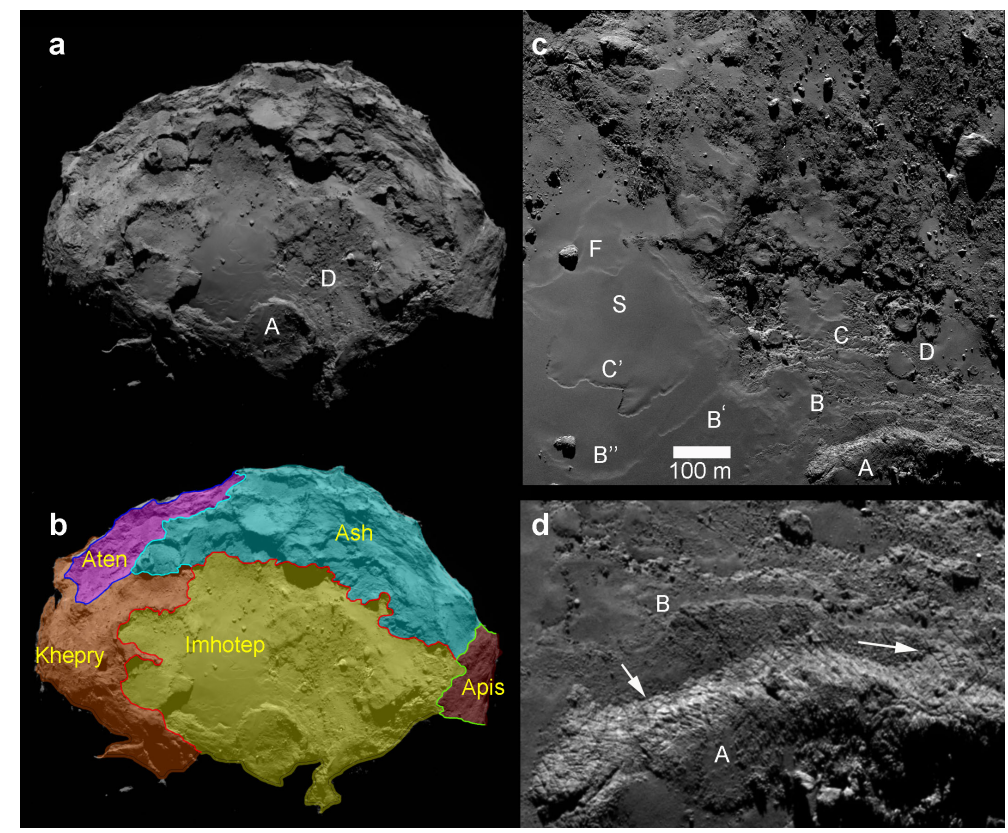

Fig. 4. a), b) WAC image of Imhotep region and a similar view with colorized regions overlapped. The Imhotep region borders The Khepry, Ash and Apis regions in addition to at least one currently non-illuminated region. c) NAC image showing the smooth deposits (S), linear features (features B', B", and $C^{\prime}$ ), circular mounds (D), possible terraces (B and C), a 40-m-wide boulder (F) and circular mesa (A). d) A close-up of the same image for the circular mesa showing the fractures that appear to form polygonal patterns in some locations (see arrows). 


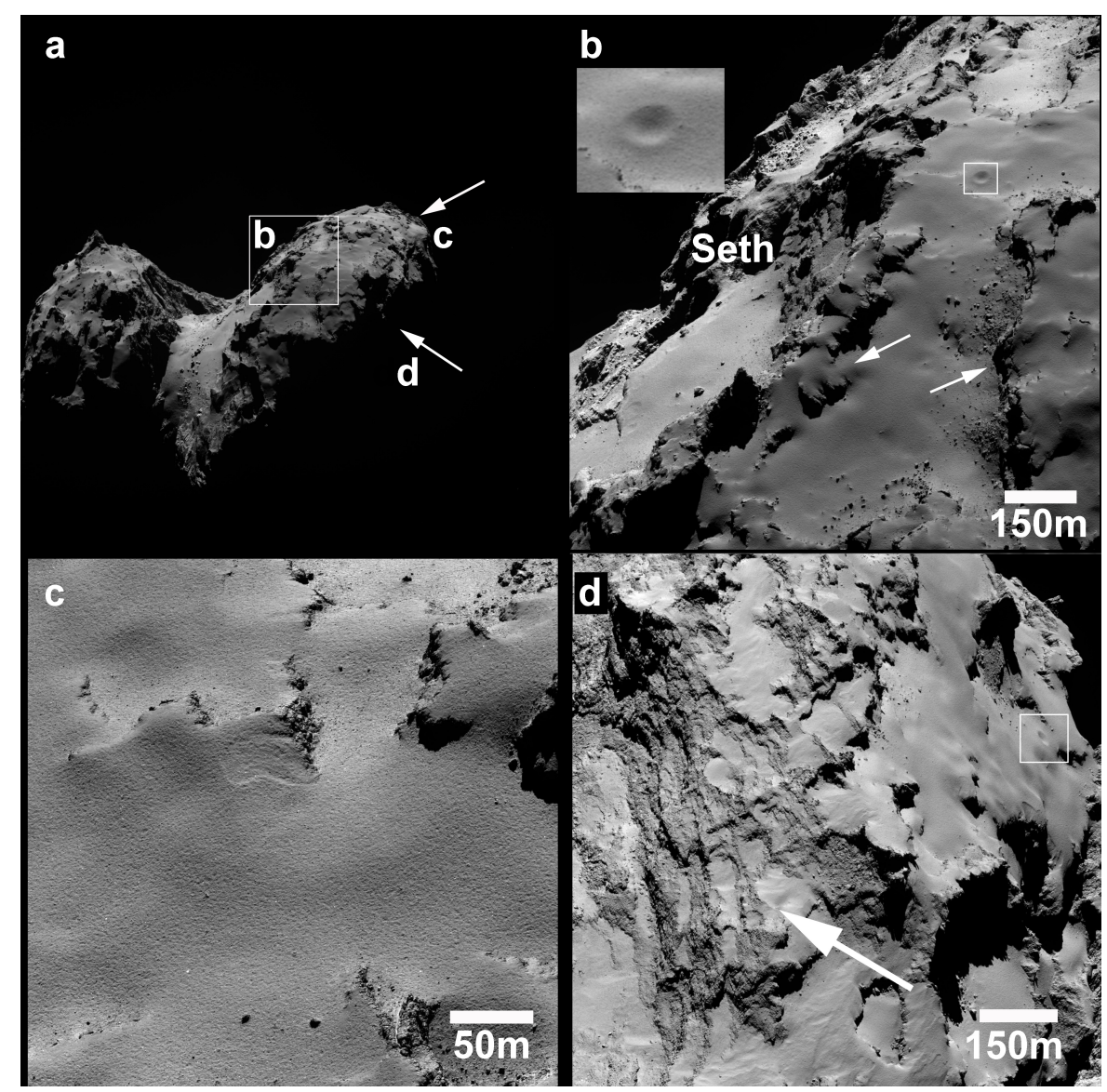

Fig. 5. WAC image showing most of the Ash region on the comet's body (right lobe). b): NAC image showing the smooth nature of the dust covering the Ash region. Box shows the location of the $40 \mathrm{~m}$-wide candidate impact crater, which is highlighted in the inbox. Arrows show locations where units resembling Seth's brittle material are exposed from beneath the dusty coating (see Sect. 3.1.4). An anaglyph of this figure is available in Appendix A. c): NAC image showing another close-up of the Ash region at higher resolution. d): NAC image showing an exposed region in Ash below the dusty coating that shows terracing and layering. The box outlines the same crater displayed in b) for orientation.

\subsubsection{Ash}

The Ash region is a dust-covered region that occupies a significant surface area of the body lobe's surface (Fig. 5). The dusty coating appears to drape mostly brittle material that outcrops in many locations in the form of debris-filled alcoves and depressions similar to Seth (Sect. 3.1.4) in addition to gradually disintegrating materials (Fig. 5b). High resolution images indicate that Ash is dominated by a generally featureless fine-grained deposit, which is mostly homogenous at the present resolution limit (Figs. 5c). Close to its boundary with Imhotep, The dusty coating gives way to what appears to be an extensive layered and terraced outcrop (Fig. 5d), which could represent the extension of the units comprising the Seth region (see Sect. 3.1.4) underlying the dust.

Another significant feature observed in Ash is a $~ 40 \mathrm{~m}$-wide bowl-shaped depression that we interpret to be an impact crater (Fig. 5b). It is not clear if the impact occurred over the dusty layer or if the crater is partially buried beneath a thin layer of newly laid-down deposits. However, we prefer the later scenario because of the lack of visible ejecta and the subdued shape of the rim. Simple impact craters on small bodies tend to show a wide range of depth to diameter ratio but roughly fall within values of 0.12 to 0.25 (see Vincent et al. 2012 and references therein). Therefore, an impact crater of such size should generally display a crater depth of $\sim 5-10 \mathrm{~m}$. Considering that the crater has not been entirely erased by the deposition of dust, we can place an upper limit on the thickness of dust, which we consider to be $\ll 10 \mathrm{~m}$.

Ash is bordered on one side by Imhotep and by Seth on the other side toward the neck. Furthermore, it is bordered southward (with respect to the comet's rotational axis) by Khepry, Aten and Babi, and by Atum and Apis on the opposite side, which lies almost perpendicular to Ash's plane (Fig. 2). The extent of the dusty coating marks the boundaries of Ash with the surrounding regions. The transition can be sharp as in the case with the Aten depression, Apis, and Atum (Sects. 3.1.5, 3.1.7, and 3.1.8, respectively), which is mainly attributed to structural/topographical boundaries (edge of depression in the case of Aten, and high ridge in the case of Atum and Apis). Conversely, the transition is gradational in the case of Babi (Sect. 3.1.6), Seth and Imhotep where the coating appears to gradually thin out exposing the underlying materials. Together, the nature of these transitions strongly suggests an airfall-like mechanism for the deposition of the dusty material, possibly driven by activity producing low velocity, non-escaping dust particles (Thomas et al. 2015).

\subsubsection{Seth}

The Seth region is the main unit on the body that is composed of brittle or weakly-consolidated materials. Collapsing of this 


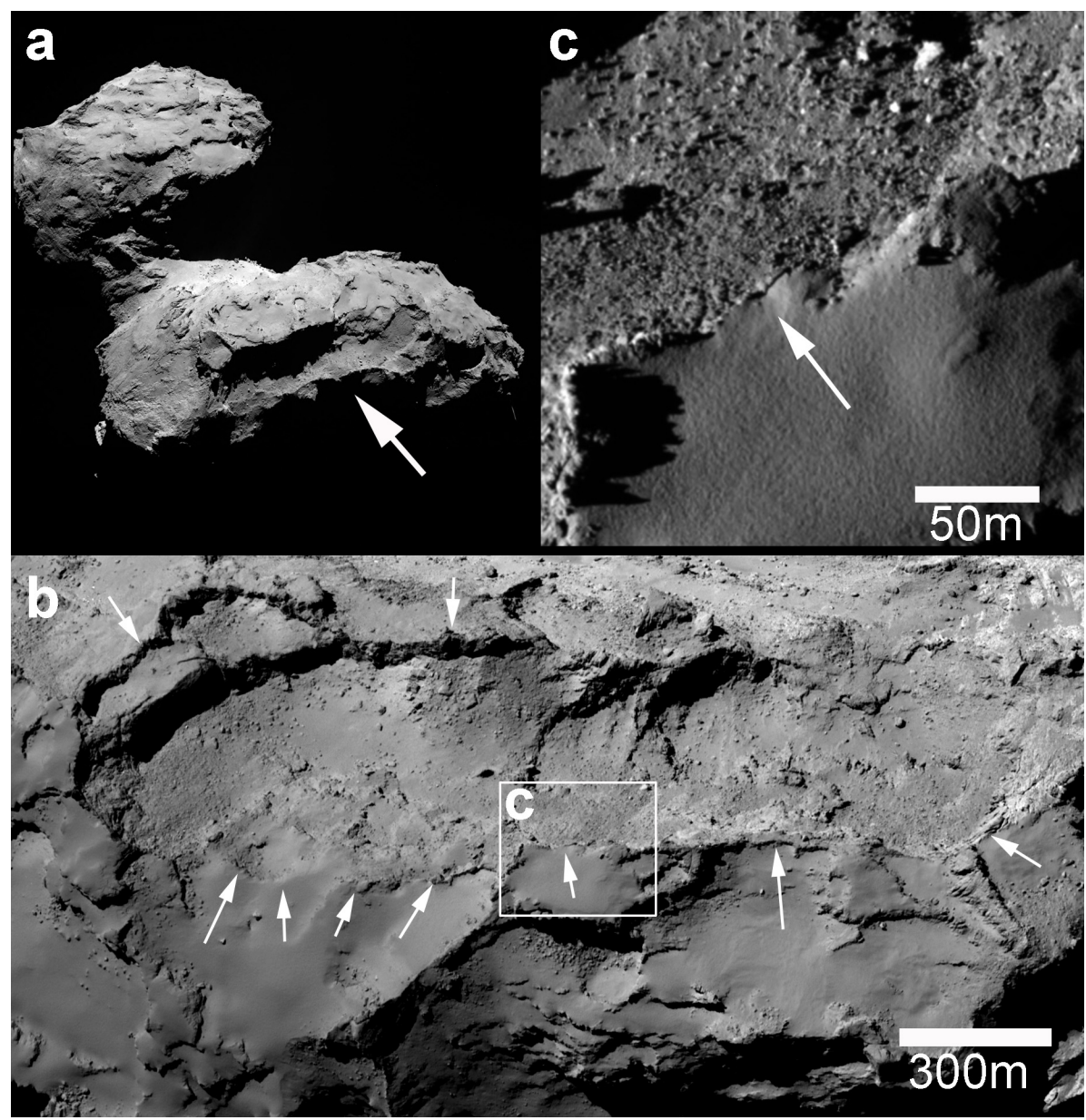

Fig. 6. a) NAC image showing the location of the Aten region on the comet's body. The region is mainly composed of a large irregular depression. b) Cropped NAC image showing the Aten depression. Note the presence of talus-like deposits resulting from material falling into the depression and the lack of smooth deposits in the interior. Box shows the position of the close up in the upper right. Arrows highlight the rim of the depression. c) Cropped NAC image showing the different morphology between the Aten's interior and the smooth deposits that are part of the Babi region. Note the sharp and irregular shape the depression's scarps, which might be indicative of short-term, possibly violent, mode of formation.

material is common and tends to form talus- and rock fall-like deposits that are darker in tone than the strongly consolidated units (Fig. A.2). There is evidence in many places of fracturing in the light-toned region; often creating polygonal patterns (Figs. A.2c, d). The Seth region is dominated by a series of flatfloored, and steep-walled circular depressions. In many cases, the Hapi facing wall (i.e., toward the neck) is absent. In some examples the flat floors hold debris presumably from collapse of the walls of the depressions. The Seth region also contains a number of circular pits. The largest is $210 \mathrm{~m}$ in diameter, $\sim 170 \mathrm{~m}$ deep, and shows evidence of dust emission from depth (Thomas et al. 2015; Vincent et al. 2015). Layering is also evident in Seth, in some cases, partially buried under a dusty cover (see Massironi et al. 2015).

Seth is bordered by Ash and Babi on one side and by Hapi on the other. The transition to Ash is gradational as the Seth terrain appears to progressively become buried by the dust material dominating Ash (see Fig. 5b). This assertion is further strengthened by similar observations we observe in the Babi region (Sect. 3.1.6). The transition to Babi is structural in nature as the Babi region appears to lie on a topographically lower level despite the similarities in morphology (see Fig. A.3b). The transition to Hapi is marked by a steep cliff, similarly to Aker. However, Seth's cliff additionally displays evidence of rock fall and talus at its foot, which is a further indication of the difference in degree of consolidation between the two regions (see Sect. 3.2 and Fig. 8b).

In addition, the Seth region has sharp boundaries with Anubis and Atum that lie almost perpendicular to the Seth-Ash plane. The scarp at the Seth-Anubis interface in particular rises $\sim 150 \mathrm{~m}$ above the Anubis terrain, which may correspond to the thickness of the Seth unit. Indeed, the scarp displays signs of mechanical failure and could be responsible for much of the taluslike deposits and boulders observed in the Atum/Anubis region (see Sect. 3.1.8 and Fig. A.7c).

\subsubsection{Aten}

Aten represents the largest irregularly-shaped depression $\left(\sim 0.12 \mathrm{~km}^{3}\right.$ in volume, Thomas et al. 2015$)$ on the body lobe of the comet (Fig. 6). It is surrounded by the brittle and dusty material of Ash and Babi. However, Aten shows no evidence of a similar dust coating within the depression. Instead the interior is covered with boulders reaching $30 \mathrm{~m}$ in diameter (Pajola et al. 2015) and talus deposits suggesting multiple rock fall events probably from failures of rim portions (Fig. 6b). At the edges of the depression, debris probably derived from disruption of consolidated brittle material is observed. The absence of smooth deposits in the interior of the basin coupled with the irregular, and occasionally sharp scarps, suggests that the depression may 
have formed through recent and short-term burst activity rather than slow long-term sublimation loss. The boundaries of the region with its surroundings are well defined by the depression's rim and are generally sharp.

\subsubsection{Babi}

The Babi region represents a transitional region in the sense that it is located at a central part of the comet's body, and shares morphological traits with the surrounding regions (Fig. A.3). For instance, Babi is composed mainly of light- and dark-toned brittle terrain, which is similar to Seth yet generally lacks the numerous circular to semi-circular features. One notable exception is the diamond-shaped structure that rises $\sim 60 \mathrm{~m}-80 \mathrm{~m}$ over the Khepry region marking the two regions' boundary and displays on its surface and flank evidence for mass-wasting as well as putative meter-sized icy boulders (Fig. A.3c, Pommerol et al. 2015). Moreover, parts of the region, particularly in proximity to the scarp with Aten, displays patches of dusty material, which are morphologically similar to the Ash region. Moreover, these dusty patches overlie locations that display remarkable layering (Fig. A.3d), which further suggests that the material dominating the Seth region is indeed extending below the dusty deposits of the Ash region and is exposed in Babi as well.

Babi is separated from Seth and Aker by well-defined ridges, as well as being topographically lower than both, and from Aten and Khepry by visible scarps. Its boundary with Ash is marked by the same scarp that separates it from Seth, yet with less relief due to the coating that thins out toward Babi (Fig. A.3d). Babi also extends toward the neck transitioning to Hapi. Similarly to Seth, the transition is marked by a steep cliff showing evidence of mass-wasting and talus debris at its foot.

\subsubsection{Apis}

Apis is a rather small region on the body's side opposite to Aker's and Khepry's. It is morphologically distinct from the neighboring region of Atum by being smoother in texture giving the appearance of a nearly flat surface (Fig. 7a). Apis appears to be composed of consolidated material that displays fracturing in many locations. Some of the fractures intersect to form some of the most notable polygonal patterns on the surface of the comet (Figs. 7b, c).

Apis appears to overlie the Atum region and is separated from Atum topographically by a small scarp as well as morphologically by a transition to the rougher terrain of Atum. It is separated from the Ash region by a clear transition to the lighter-toned terrain of Ash (Fig. 7a). Finally, the boundary with Imhotep has already been discussed.

\subsubsection{Atum and Anubis}

The Atum region is one of the prominent rough-textured and complex regions on the same side of the body as, and bordering, the Apis region. Atum shows minimal bouldering but several small complex depressions showing lineaments (Fig. A.5).

Atum borders the smooth-textured Anubis region and almost encloses it. However, its boundaries with the region are not always clear-cut. It is separated from the Ash and Seth regions by a well-defined ridge, which shows pervasive polygonal fracturing on the Seth-facing side. Interestingly, Atum appears to share a boundary with the Anuket region in the head lobe that appears to traverse the neck region in an area devoid of smooth

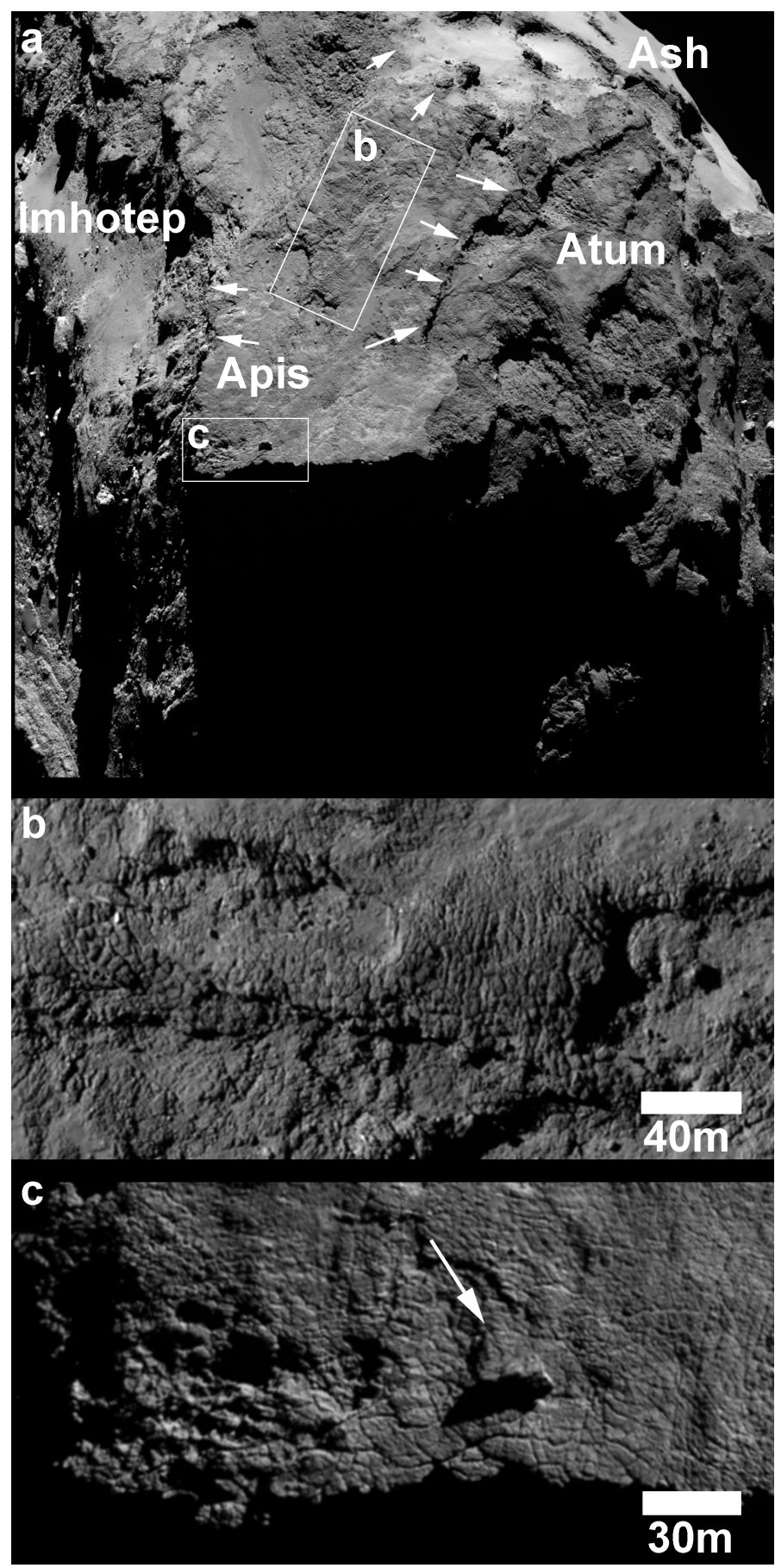

Fig. 7. a) NAC image showing the Apis region and its surroundings. Note the region's dark tone in comparison to Ash and its flat appearance in comparison to Atum. Arrows point to locations of the boundaries between adjacent regions $\mathbf{b}$ ) and c) Cropped parts of a NAC image showing the polygonal fracture patterns in the region. The view in $\mathbf{b}$ ) is rotated $110^{\circ}$ anticlockwise with respect to a). Note the large $30 \mathrm{~m}$-long boulder in c) (arrow), which appears to be fractured as well.

deposits (see Sect. 3.3.2 and Fig. 8a). A scarp marks the boundary between both regions as the Atum region develops into a cliff toward the neck in a way similar to Babi and Seth. Finally, the region may extend into the non-illuminated areas so its full extent is not yet determined.

The Anubis region borders and is almost enclosed by the Atum region (Fig. A.7). In this respect, it is similar to Imhotep's smooth terrain that is similarly enclosed by more consolidated 


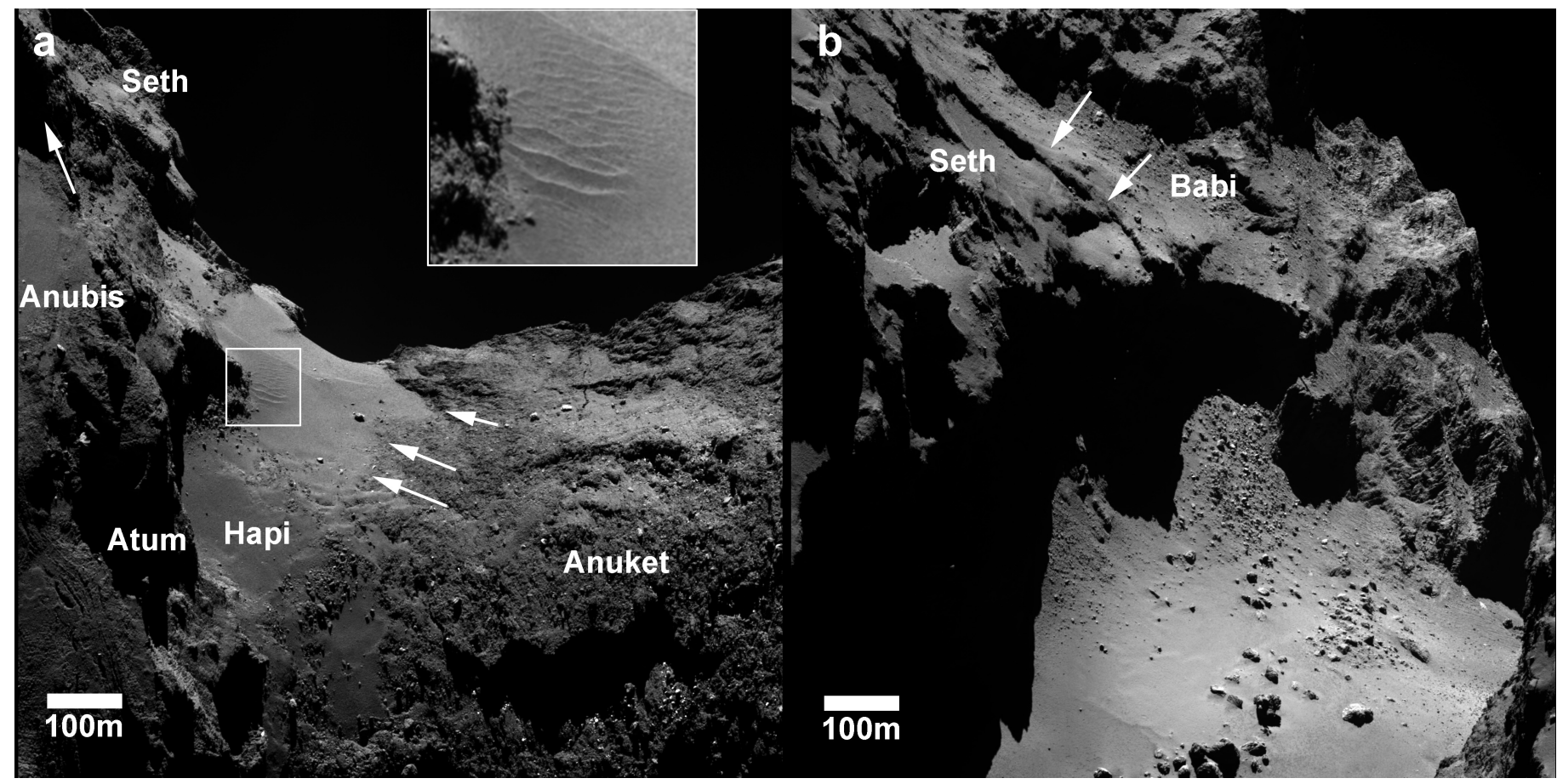

Fig. 8. a) NAC image showing the section of Hapi facing the Anuket region. The region is distinguished by its smooth texture, which show surface ripples (inbox) indicative of dust mobilization by aeolian-like processes. The folded section of Anubis is visible as well in the bottom left corner. Note how the Anuket material appears to traverse the neck region in the lower section of the image creating a boundary with Atum. b) NAC image showing part of the Hapi region facing the Hathor cliffs (outside the right bounds of the image), which is roughly beyond the horizon of a). Also visible in the foreground is the line of boulders along this section of the region in addition to the scarp boundaries with Seth and Babi. Arrows in both figures point to locations of the boundaries between adjacent regions.

material (Khepry). In addition, the region displays linear features that are similar to that observed in Imhotep (compare Fig. A.7a and feature $\mathrm{C}^{\prime}$ in Fig. 4c), and can be interpreted as an expression of terraces caused by erosion of a layered terrain. Another notable feature in Anubis is located at the interface with Seth, which comprises a set of parallel curved lineaments indicating possible folding or a surface expression of buried terraces (Fig. A.7b).

\subsection{Neck (Hapi)}

The visible view of the neck area is currently dominated by one surface texture and, as such, is currently regarded as a single region named Hapi. The only exception is a narrow rough section that morphologically looks like an extension of the Anuket region on the head lobe (Sect. 3.3.2, Fig. 8a). The Hapi region was the first unit to become visibly active (dust emitting) in OSIRIS images (Thomas et al. 2015; Sierks et al. 2015). This region is fairly smooth and narrow leading to its neck-like appearance (Thomas et al. 2015). Unlike Imhotep, the smooth material forming Hapi is piled up against the faces of Hathor and Seth in several places. A small dune field is also observed (Fig. 8a) and several boulders appear to have wind tails indicating that aeolian dust transport may be of significance. The region also displays a concentration of boulders aligned in an almost linear pattern at the part of the region opposite to the Hathor cliffs (Fig. 8b).

The Hapi region serves as a transitional region between the comet's two lobes and is morphologically distinct from the neighboring regions of Seth, Atum, Aker and Babi on the body lobe, and Hathor and Anuket on the head lobe, by its smooth appearance and topographically lower setting with respect to the comet's rotational axis.

\subsection{Head lobe}

\subsubsection{Hathor}

Hathor mostly comprises a 900 m high "cliff" which rises up from the Hapi region almost perpendicular to the comet's equatorial plane (Fig. 9). This region is characterized by a set of aligned lineaments and fractures which run vertically upwards for much of the height of the cliff and roughly perpendicular lineaments aligned with small terraces which might suggest inner layering (Thomas et al. 2015). Together, they form a rectilinear morphology that gives the cliff a very distinctive texture. Of particular interest in the Hathor region is an alcove structure that appears brighter and smoother than its surroundings in some of the early lower spatial resolution images and devoid of the linear features that are dominant in Hathor (Fig. 9a). However, at higher resolution and different illumination geometry (Fig. 9b), the alcove appears rougher, though still devoid of horizontal lineations, and shows longitudinal terraces (i.e., perpendicular to the neck plane) that could be suggestive of concentric layering in the head lobe (see also Marchi et al. 2015; Massironi et al. 2015). Another interesting feature in the region is a block of material that appears to protrude from the center of the cliff and shows similar surface lineations to the background (A in Fig. 9a). The irregular shape of the feature, its protruding nature, and surface texture suggest it may have partly detached from the cliff.

Hathor is separated from the Anuket region at its lower sections at the mentioned alcove closest to the neck where a shift in surface morphology is apparent. The orientation of the Hathor alcove and the boundary with Anuket suggests that Hathor may be representative of the internal structure of the head lobe underlying the Anuket unit. Morphological heterogeneity also defines Hathor's boundaries with the smooth-textured Hapi and Ma'at 


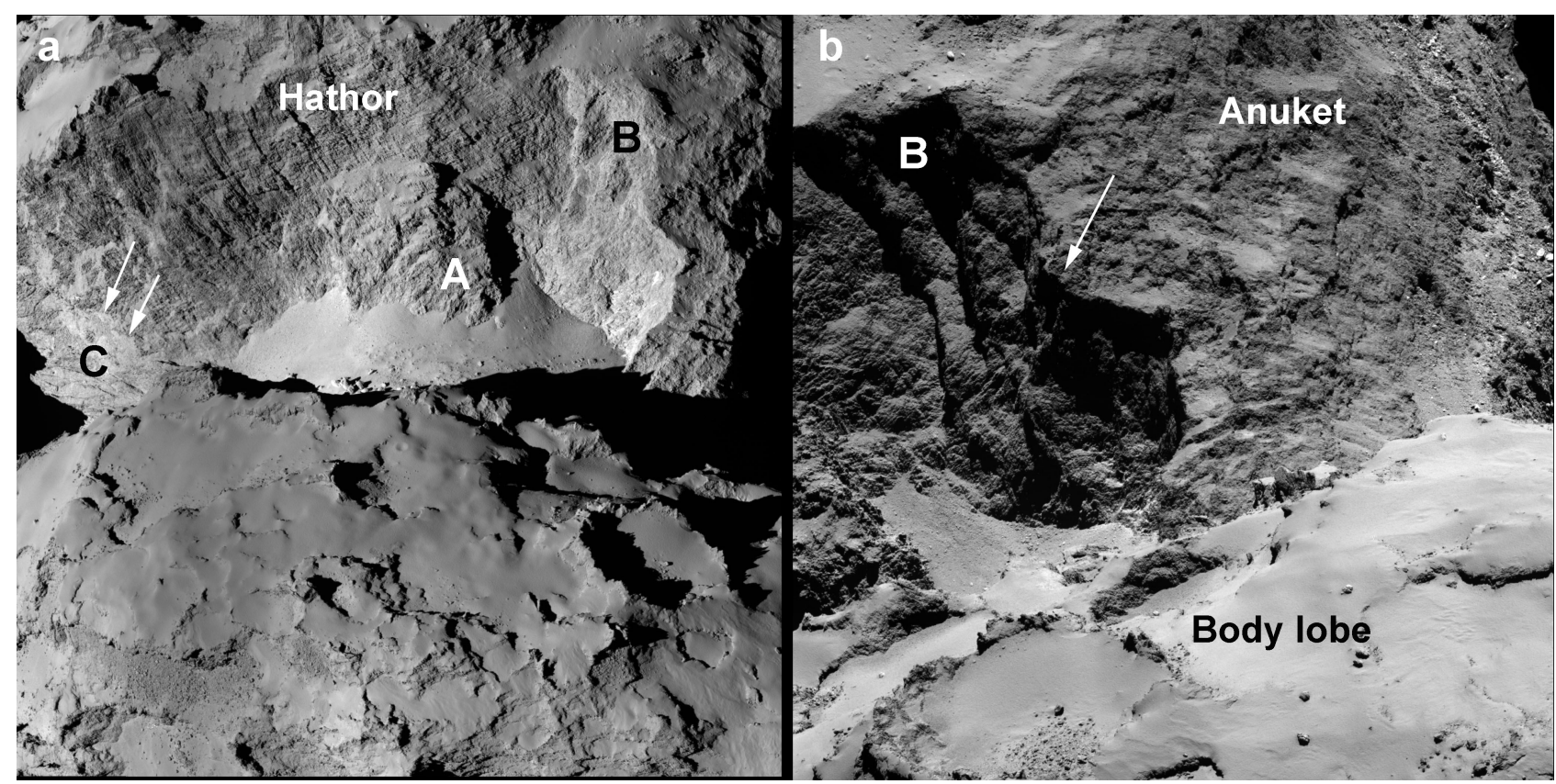

Fig. 9. a) NAC image showing the Hathor region with the body lobe in the foreground. The region comprises a cliff-like structure with rectilinear lineations that distinguish it from other consolidated and fractured regions such as Bastet (boundary highlighted by arrows). Notable features in the region include an alcove structure that appears brighter and smoother than than its surrounding at this illumination angle (B) and protruding, possibly detached, block of material (A) that shows similar surface features to the background. Anaglyphs of this image, as well as b), are available in Figs. A.8 and A.9, which highlights the complex morphology of the cliff and the transition to Bastet at feature (C) and associated arrows. b) NAC image highlighting the alcove structure (B), which in this viewing geometry shows longitudinal terraces, which could hint at concentric layering of the head lobe. Notice the sharp contact with Anuket (arrow), which further suggests that Hathor is an outcrop for the internal structure of the comet below the overlying Anuket materials.

regions. Finally, the boundary with Bastet is defined by a structural/geometric transition (Figs. 9a and A.8) where the plane of the Bastet region appears to be perpendicular to that of Hathor as well as a morphological one as Bastet displays a similarly consolidated and fractured surface texture, albeit a more irregularly lineated one.

\subsubsection{Anuket}

Anuket borders Hathor and appears to be similarly consolidated but shows no evidence of the lineament patterns observed in Hathor (Fig. 10). Anuket has a rough surface with numerous boulders but tends to smooth out away from the neck and toward the boundary with Ma'at. The rougher sections of the region have a very distinctive morphology that almost resembles a "melted wax" texture. A notable feature visible in the lower section of the regions adjacent to Hapi is a $\sim 500 \mathrm{~m}$-long linear fracture. The presence of such a fracture close to the neck region could be attributed to rotational- or orbital-induced stresses in that specific part of the comet and merits further investigation.

Anuket is bordered by Hathor (see Sect. 3.3.1), Serqet, Ma'at and Maftet on the head lobe in addition to Hapi and the Atum region on the body. WAC views of the nucleus indicate that the contact between Anuket and Serqet is associated with a ridge (Fig. 10a) whereas the boundary with Ma'at, while structurally defined by the same ridge, is morphologically gradational (Fig. 10b). Inspection of images taken at high resolution $(\sim 0.20 \mathrm{~m} / \mathrm{px})$ of the part of Anuket that appears to smoothen toward Ma'at shows that this smoothing is caused by patches of dust covering parts of the Anuket region close to Ma'at (Fig. 10d). This suggests that material similar to that of Anuket's surface may extend underneath the dust-covered
Ma'at region (with both overlying Hathor stratigraphically, see Sect. 3.3.1). Finally, Anuket is separated from Hapi and Maftet regions through clear morphological heterogeneity.

\subsubsection{Ma'at}

Ma'at is a dust-covered region that resembles Ash on the comet's body in terms of overall morphology (Fig. A.10). The dusty coating is similarly featureless except for the regions around the Hatmehit depression where striations or ripple-like features are visible, which may indicate some degree of mobilization (Figs. A.10b,c). Many sharp outcrops of materials buried beneath the dust are visible in the region, which probably correspond to consolidated materials potentially similar to Anuket. Interestingly, outcrops of Seth-like brittle materials are rare, which may indicate a degree of heterogeneity between the comet's lobes.

Ma'at is bordered by all currently identified regions on the head lobe. The transitions are either textural (defined by the extent of the dust coverage), structural, or both. For instance, the transition with Maftet is gradational as the dust appears to gradually thin out. In the case of Anuket, there is a clear topographical boundary between the two regions. However, discontinuous patches of dust are observed at Anuket beyond the topographical boundary (see Sect. 3.3.2, Fig. 10d). Ma' at has sharp boundaries with the cliffs of Hathor and the rims of Nut and Hatmehit although parts of Hatmehit's interior may include some dust. The boundary with Bastet is both structural and morphological as they appear to be separated by a scarp (see Sect. 3.3.6 and Fig. A.12a). 


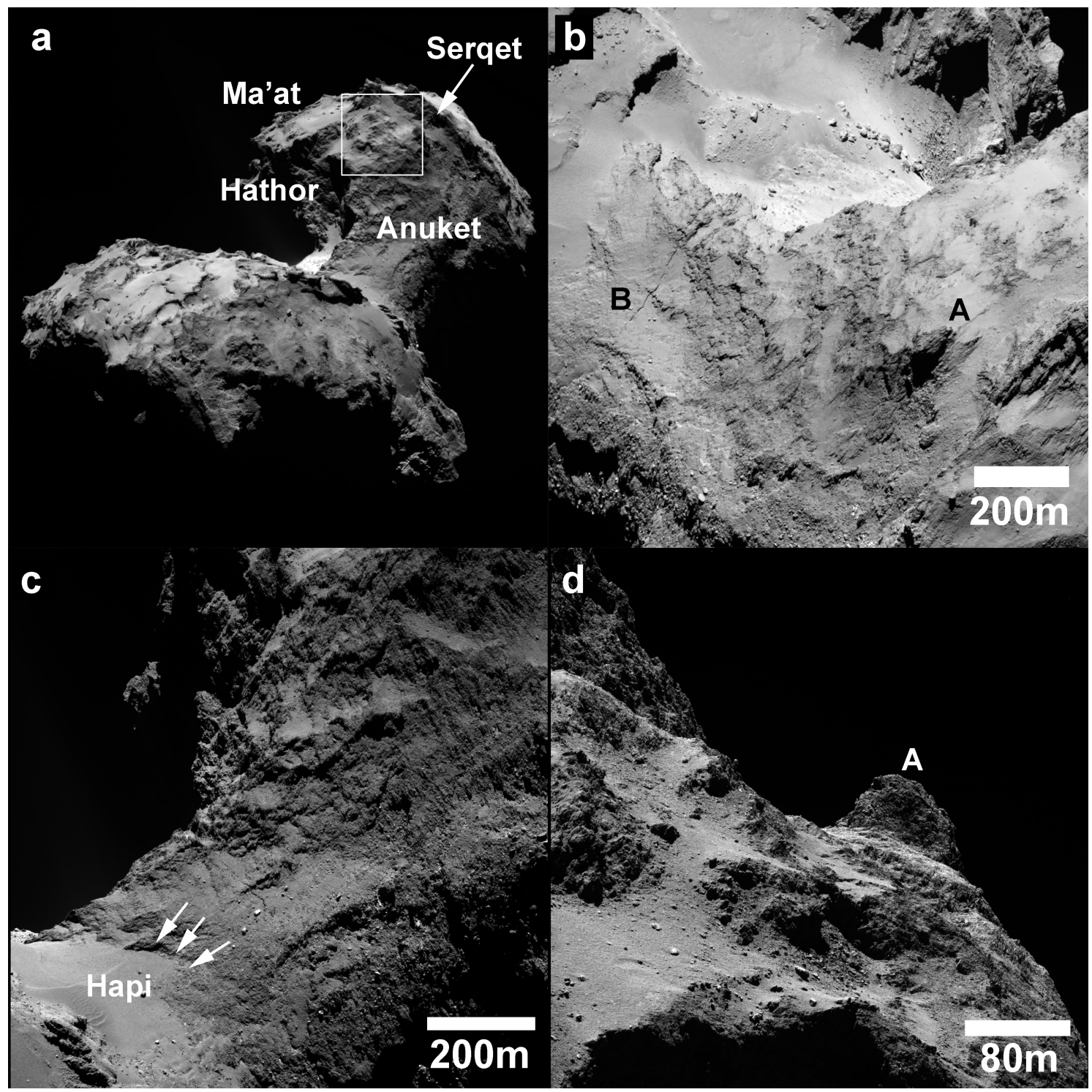

Fig. 10. a) WAC image showing the Anuket region. Note the sharp scarp that separates it from Hathor and the ridge (arrow) that separates it from Serqet. The box shows the approximate location of d). b) A crop of NAC image showing the Anuket region in more detail. The region shows a distinctive morphology resembling melted-wax texture. Overall, the region is rough but smoothen out a little as it approaches Ma'at (toward the right of the image). A notable feature in Anuket is a $\sim 500 \mathrm{~m}$-long fracture that runs across the region (feature B). A particular knob (A) is marked to correlate it with another viewing angle in d). c) NAC image showing another view of Anuket at different lighting conditions, which highlights the region's distinctive texture. Note the absence of lineations that dominate the adjacent Hathor region. Arrows point to parts of the boundary between Anuket and Hapi d) NAC image taken at low orbit $(\sim 10 \mathrm{~km})$ showing part of Anuket that is relatively smooth, which can be shown in this image to be caused by partial burial of the region by patches of debris resembling that of Ma'at. This image is a strong indicator that the Anuket surface material may extend below the Ma'at debris.

\subsubsection{Serqet and Nut}

The Nut depression and Serqet are two of the smallest regions on the surface of the comet in terms of surface area, but show remarkable morphological diversity (Fig. 11). The Serqet region is mainly composed of a ridge of consolidated material, which separates the distal regions (i.e., Ma'at, Serqet, Nut, Hatmehit and Maftet) from Anuket and Hathor, and a flat and smooth plain adjacent to it, which appears to be dust-covered. The smooth plain develops into the rim of Nut. The Nut depression may be similar to other depressions on the comet such as Hatmehit and Aten although this is difficult to evaluate because of the extensive boulder debris filling it, which may have resulted from the erosion of Serqet in addition to potential dust cover similar to that of Ma'at (Fig. 11b).

\subsubsection{Maftet}

Maftet is a rough, multi-terraced, and generally fractured region (Fig. 12). The region is composed of rough-textured and fractured material enclosing numerous irregularly-shaped shallow depressions, which are reminiscent of similar features in Atum. Parts of its boundary with Ma'at shows patches of the fading dusty material showing a pitted texture (Fig. 12c), which suggests that the dusty layer is an ice-rich material that may be undergoing desiccation through sublimation. The higher plateau shows pervasive fracturing in many locations that occasionally grades into polygonal fracturing (Fig. 12d). A notable feature in Maftet is a $35 \mathrm{~m}$-wide pit that's shows features suggestive of a fluidized outflowing material (Thomas et al. 2015, Fig. A.11). 


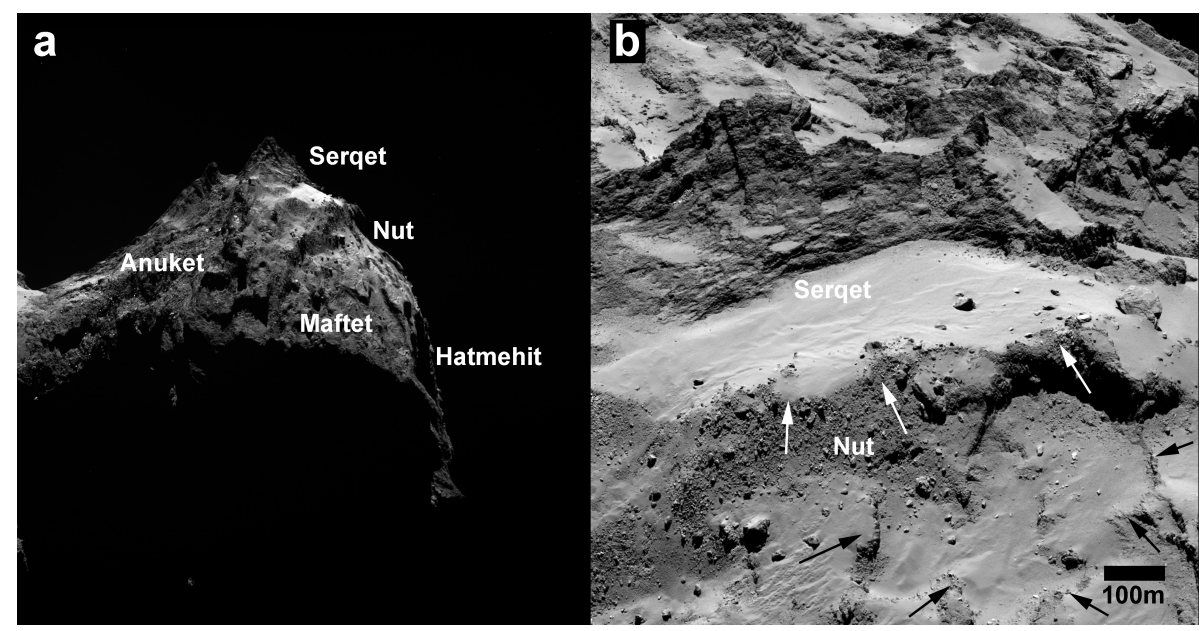

Fig. 11. WAC image showing a side view of the Serqet and Nut regions. Serqet is mainly composed of ridge, which separates it and other region on the distal part of the lobe from the inner regions toward the neck, and a smooth flat plain that forms the rim of the Nut depression. b) NAC image highlighting the morphological features. Note that both Serqet and Nut are covered by patches of Ma'at debris, which is occasionally striated. In addition, the part of Nut region adjacent to Serqet plain material is covered by boulders and talus that may have formed through the erosion of the Serqet region. Arrows point to locations of the boundary between Nut and Serqet as well as its surroundings.

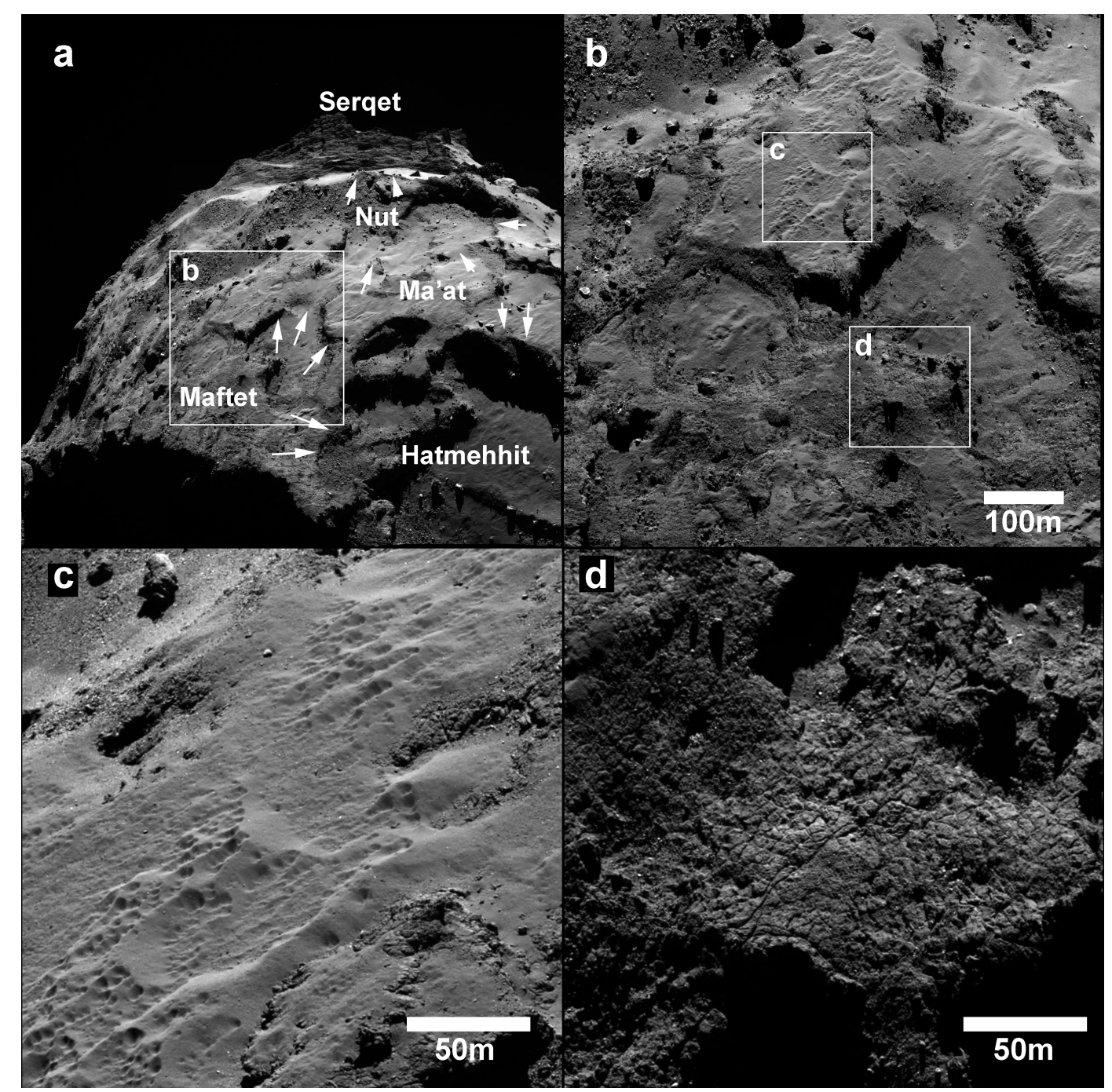

Fig. 12. a) WAC image showing the Maftet region and its surroundings. Arrows point to locations of the boundaries between adjacent regions. b) NAC image showing the surface morphology of the Maftet region. The region is mainly composed of rough and fractured terrain enclosing numerous irregular and heavily bouldered depressions. c) Crop of NAC image showing the pitted texture in the debris at the boundary between Maftet and Ma'at. d) Crop of NAC image showing the pervasive fracturing, which is a common feature in Maftet. 
This material creates a tongue-shaped deposit that appears to flow away from the pit for $\sim 75 \mathrm{~m}$.

Maftet is neighbored by the two major depressions Nut and Hatmehit, in addition to Ma'at, Serqet, and Anuket. The transition to Ma'at is gradational in terms of morphology whereas the transition to Serqet and Anuket is sharper and characterized by a change in both topography and surface morphology. Finally, Maftet may yet extend to the currently non-illuminated areas.

\subsubsection{Bastet}

The Bastet region is another consolidated and heavily lineated region that lies adjacent to the Hatmehit region and opposite to Maftet (Fig. A.12). The region is generally fractured but interestingly shows a preferred alignment of long lineaments, which run roughly parallel to each other yet with some degree of crosscutting (Fig. A.12b). The lineaments are not clearly visible close to the boundaries with Hatmehit and Ma'at but tend to develop toward the central part of the region. Another interesting feature is the presence of a few quasi-circular alcoves that show evidence for mass-wasting in their interiors (Fig. A.12b), which is reminiscent of the landforms observed at Seth.

Bastet is bordered by the Hatmehit, Ma'at and Hathor regions and shows clear morphological transitions with all three that have been discussed already. Finally, the region may yet extend into parts of the non-illuminated areas.

\subsubsection{Hatmehit}

Hatmehit is a circular depression $\sim 1.0 \mathrm{~km}$ in diameter (Fig. A.13). The flat-floored depression is surrounded by rim materials that appear to be more consolidated than the interior of the depression and resemble the neighboring region of Bastet in terms of morphology. The interior of the depression contains numerous boulders of variable size reaching a maximum dimension of $30 \mathrm{~m}$ in diameter and is dominated by a smooth texture except for a debris-covered section adjacent to Bastet. Another notable feature is the presence of hogback-like curvilinear ridge that runs through the depression's floor and below the talus-like debris.

Hatmehit is surrounded by the regions of Maftet, Ma' at and Bastet in addition to a currently non-illuminated region. The rim of the depression marks its boundary with all these regions.

\section{Morphological comparison to other Jupiter family comets}

Comet 67P has been imaged in unprecedented high spatial resolution, which would make it difficult to fully compare its surface to the nuclei of Jupiter family comets (JFCs) that have been visited by other space missions (see Keller et al. 2004; Thomas 2009; and Cheng et al. 2013, for comprehensive overviews of in situ observations of cometary nuclei). Nevertheless, some comparisons can be made with JFCs that have been imaged at $\sim 8-15 \mathrm{~m} / \mathrm{pixel}$, which include comets 81P/Wild 2, 103P/Hartley 2, and 9P/Tempel 1.

Interestingly, 67P combines some of the notable morphologies that were considered to be distinctive features of the previously observed comets. Namely, circular flat-floored pits in Wild 2 (Brownlee et al. 2004), circular features and layering possibly triggered by fluidization processes on Tempel 1 (Belton and Melosh, 2009), and extremely smooth terrains, on Hartley 2 (A'Hearn et al. 2011) as well as its overall bi-lobed shape. We briefly describe here the similarities to Wild 2 and Hartley 2 while the similarities between the circular features on
Tempel 1 and those observed in the Imhotep region (Fig. 4) are addressed in detail by Auger et al. (2015). Circular and semicircular flat-floored features are observed mainly in the Seth region and appear to be composed of weakly consolidated materials that occasionally collapse forming debris and talus-like deposits (these should not be confused with the "active pits" (see Vincent et al. 2015, and Table 1) that show generally larger d/D ratios). However, these features are roughly an order of magnitude smaller than the 1-2 km-wide depressions in Wild 2, which were interpreted to be impact craters in a layered porous surface (Brownlee et al. 2004). This interpretation was slightly modified by Cheng et al. (2013) who suggested that the depressions started as much smaller impact craters and later grew in size through erosion. In addition, considering that the flat-floored depressions on 67P appear to be concentrated in a single region, it seems unlikely that the Seth depressions were caused by impacts.

With regards to comet Hartley 2, there are a couple of similarities worth noting. First, the bi-lobed shapes of Hartley 2 and $67 \mathrm{P}$ are generally similar although Hartley 2's mean radius is roughly 4 times smaller than that of 67P (A'Hearn et al. 2011; Thomas et al. 2013). Moreover, Hartley 2 shows a distinctive "band" of smooth deposits, which similarly to 67P, appears to be concentrated in the neck region (or "waist" as defined by A'Hearn et al. 2011). A'Hearn et al. (2011) proposed that the smooth deposits on Hartley 2 were formed either through infall in a gravitational low, or though in-situ fluidization of regolith induced by out-flowing gas. Both mechanisms appear to be viable for comet $67 \mathrm{P}$ as well. Therefore, it appears that the smooth materials in both comets may share a single formation mechanism.

\section{Summary}

We have identified 19 regions on the currently illuminated surface of comet 67P using images from the OSIRIS camera. Since $\sim 30 \%$ of the comet surface is currently in shadow, yet expected to be illuminated in later phases of the mission, it is expected that more regions will be added. The surface of the nucleus displays a remarkable morphological diversity but can be broadly classified into 1) consolidated regions (strongly consolidated and brittle regions); 2) non-consolidated regions (smooth terrains and dust-covered regions); and 3) large irregular depressions.

Consolidated regions represent the most common region type on both lobes. In addition, consolidated materials are observed even in dust-dominated and smooth regions (see below). Most of the consolidated regions, especially the strongly consolidated ones, show variable degrees of fracturing, which include irregular, polygonal, or oriented. The ubiquitous presence of fractured materials on the surface of the comet is of paramount significance for a body that displays very low bulk density, which may indicate certain heterogeneity within the comet in terms of composition and physical parameters such as porosity. Consolidated materials on the comet are fully exposed, partially buried by dust or enclose smooth terrains.

A smaller sub-category of these consolidated regions includes brittle/weakly consolidated units. These units are mainly located in the Seth region and Babi on the body lobe and to a much lesser extent in Bastet in addition to limited exposures beneath Ma'at on the head lobe, which may indicate a certain degree of compositional heterogeneity between the lobes. The brittle terrains show a high concentration of circular pits, and mass-wasting deposits in alcove-like features. However, they also show signs of consolidation such as fracturing in some 
locations. Non-consolidated regions comprise two main sub categories: smooth terrains and dust covered regions. Smooth terrains mainly encompass Imhotep, Anubis on the body lobe and Hapi in the neck region. However, other regions show patches or isolated areas of smooth deposits such as Khepry and Serqet. The regions are generally covered with smooth deposits that show variable degree of lateral mobilization such as ripple- and dune-like features. They occasionally contain many boulders and may represent areas of current or past prolonged activity.

Dust-covered regions mainly encompass the Ash and Ma' at regions although variable and isolated patches of dust are observed in other regions as well such as Seth and Babi on the body lobe, and Anuket and Maftet on the head lobe. The boundaries of Ash and Ma' at are usually gradational as the dusty coating gradually thins out, which is strongly suggestive of an airfall-like mechanism for the deposition of the dust, most probably linked to surface activity. In many locations in these regions, outcrops of underlying materials are exposed, which morphologically resemble strongly consolidated materials in the case of Ma' at and brittle materials in the case of Ash.

Finally, the surface of the comet currently displays three large irregularly-shaped depressions: Hatmehit and Nut on the head lobe, and Aten on the body lobe. Their interiors are mostly filled with mass-wasting or talus-like deposits, yet generally lack dusty covers. This trend is particularly noticeable in Aten, which is surrounded by dust-covered terrains. The three depressions display sizes, shapes, and depth-to-diameter ratios that are difficult to reconcile with an impact hypothesis and may represent locations of massive outbursts of activity or other endogenic processes.

Acknowledgements. OSIRIS was built by a consortium of the Max-PlanckInstitut für Sonnensystemforschung, in Göttingen, Germany, CISAS-University of Padova, Italy, the Laboratoire d'Astrophysique de Marseille, France, the Instituto de Astrofísica de Andalucia, CSIC, Granada, Spain, the Research and Scientific Support Department of the European Space Agency, Noordwijk, The Netherlands, the Instituto Nacional de Técnica Aeroespacial, Madrid, Spain, the Universidad Politéchnica de Madrid, Spain, the Department of Physics and Astronomy of Uppsala University, Sweden, and the Institut für Datentechnik und Kommunikationsnetze der Technischen Universität Braunschweig, Germany. The support of the national funding agencies of Germany (DLR), France (CNES), Italy (ASI), Spain (MEC), Sweden (SNSB), and the ESA Technical Directorate is gratefully acknowledged. We thank the ESA teams at ESAC, ESOC and ESTEC for their work in support of the Rosetta mission. We also thank Carle Pieters for her insightful review of the paper.

\section{References}

A'Hearn, M. F., Belton, M. J. S., Delamere, W. A., et al. 2011, Science, 332, 1396

Auger, A.-T., Groussin, O., Jorda, L., et al. 2015, A\&A, 583, A35

Brownlee, D. E., Horz, F., Newburn, R. L., et al. 2004, Science, 304, 1764

Cheng, A. F., Lisse, C. M., \& A'Hearn, M. 2013, Icarus, 222, 808

Keller, H. U., Britt, D., Buratti, B. J., \& Thomas, N. 2004, In situ observations of cometary nuclei, eds. M. C. Festou, H. U. Keller, \& H. A. Weaver, 211

Keller, H. U., Barbieri, C., Lamy, P., et al. 2007, Space Sci. Rev., 128, 433

Keller, H. U., Mottola, S., Davidsson, B., et al. 2015, A\&A, 583, A34

Marchi, S., Rickman, H., Massironi, M., et al. 2015, in A\&A Lunar and Planetary Science Conference, 46, 1532

Massironi, M., Marchi, S., Pajola, M., et al. 2012, Planet. Space Sci., 66, 125

Massironi, M., Simioni, E., Marzari, F., et al. 2015, Nature, submitted Pajola, M., Vincent, J.-B., Güttler, C., et al. 2015, A\&A, 583, A37 Pommerol, A., Thomas, N., El-Maarry, M. R., et al. 2015, A\&A, 583, A25

Sierks, H., Barbieri, C., Lamy, P. L., et al. 2015, Science, 347, 1044
Thomas, N. 2009, Planet. Space Sci., 57, 1106

Thomas, N., Barbieri, C., Keller, H. U., et al. 2012, Planet. Space Sci., 66, 96 Thomas, N., Davidsson, B., El-Maarry, M. R., et al. 2015a, A\&A, 583, A17

Thomas, N., Sierks, H., Barbieri, C., et al. 2015b, Science, 347, 440

Thomas, P. C., A'Hearn, M. F., Veverka, J., et al. 2013, Icarus, 222, 550

Vincent, J.-B., Besse, S., Marchi, S., et al. 2012, Planet. Space Sci., 66, 79

Vincent, J.-P., Bodewits, D., Besse, S., et al. 2015, Nature, 523, 63

1 Physikalisches Institut, Sidlerstr. 5, University of Bern, 3012 Bern, Switzerland

e-mail: mohammed.elmaarry@space.unibe.ch

2 Dipartimento di Geoscienze, University of Padova, via G. Gradenigo 6, 35131 Padova, Italy

3 Centro di Ateneo di Studi ed Attivitá Spaziali, "Giuseppe Colombo" (CISAS), University of Padova, 35122 Padova, Italy

4 Max-Planck-Institut für Sonnensystemforschung, Justus-vonLiebig-Weg, 3, 37077 Göttingen, Germany

5 INAF-78Osservatorio Astronomico, vicolo dell'Osservatorio 5, 35122 Padova, Italy

6 Aix-Marseille Université, CNRS, LAM, UMR 7326, 38 rue Frédéric Joliot-Curie, 13388 Marseille, France

7 International Space Science Institute, Hallerstraße 6, 3012 Bern, Switzerland and Centro de Astrobiología, CSIC-INTA, 28850 Torrejón de Ardoz, Madrid, Spain

8 Department of Physics and Astronomy, Uppsala University, Box 516, 75120 Uppsala, Sweden and PAS Space Research Center, Bartycka 18A, 00716 Warszawa, Poland

9 Scientific Support Office, European Space Agency, 2201 Noordwijk, The Netherlands

10 Institute for Geophysics and Extraterrestrial Physics, TU Braunschweig, 38106 Braunschweig, Germany

11 Department of Astronomy, University of Maryland, College Park, MD, 20742-2421, USA

12 LESIA, Obs. de Paris, CNRS, Univ Paris 06, Univ. Paris-Diderot, 5 place J. Janssen, 92195 Meudon, France

13 LATMOS, CNRS/UVSQ/IPSL, 11 boulevard d'Alembert, 78280 Guyancourt, France

14 Centro di Ateneo di Studi ed Attivitá Spaziali, "Giuseppe Colombo" (CISAS), University of Padova, 35122 Padova, Italy

15 CNR-IFN UOS Padova LUXOR, Via Trasea, 7, 35131 Padova, Italy

16 Department of Physics and Astronomy, Uppsala University, 75120 Uppsala, Sweden

17 UNITN, Universitá di Trento, Via Mesiano, 77, 38100 Trento, Italy

18 Department of Mechanical Engineering - University of Padova, via Venezia 1, 35131 Padova, Italy

19 INAF-Osservatorio Astronomico, Via Tiepolo 11, 34014 Trieste, Italy

20 Instituto de Astrofísica de Andalucía (CSIC), c/ Glorieta de la Astronomía s/n, 18008 Granada, Spain

21 Deutsches Zentrum für Luft- und Raumfahrt (DLR), Institut für Planetenforschung, Rutherfordstraße 2, 12489 Berlin, Germany

22 National Central University, Graduate Institute of Astronomy, 300 Chung-Da Rd, 32054 Chung-Li, Taiwan

23 Laboratoire d'Astrophysique de Marseille, 38 rue de Frédéric JoliotCurie, 13388 Marseille Cedex 13, France

24 Scientific Support Office, European Space Astronomy Centre/ESA, PO Box 78, 28691 Villanueva de la Canada, Madrid, Spain

25 Solar System Exploration Research Virtual Institute, Southwest Research Institute, 1050 Walnut St., Suite 300, Boulder, CO 80302, USA

26 Institut für Datentechnik und Kommunikationsnetze der TU Braunschweig, Hans-Sommer-Str. 66, 38106 Braunschweig, Germany

27 University of Padova, Department of Information Engineering, via Gradenigo 6/B, 35131 Padova, Italy 
Table 2. Basic description and morphology of the various regions that are described in the main text.

\begin{tabular}{|c|c|c|c|}
\hline Region & Region type & Description & Notable feature(s) \\
\hline \multicolumn{4}{|c|}{ Body } \\
\hline Khepry & Strongly consolidated & $\begin{array}{l}\text { Rough- and bright-looking unit neighboring the Imhotep, Aten, } \\
\text { Babi, and Aker regions. Moderately lineated. Rough in compar- } \\
\text { ison to Aker although transition to it is gradual. }\end{array}$ & $\begin{array}{l}\text { - Numerous ponds of smooth } \\
\text { deposits }\end{array}$ \\
\hline Aker & Strongly consolidated & $\begin{array}{l}\text { Dark-toned unit with a mixed degree of roughness. Lineated } \\
\text { and showing tectonic-like features. Possibly a reworked section } \\
\text { of the Khepry region. Several small smooth areas are evident. }\end{array}$ & - $200 \mathrm{~m}$-long angular fractures \\
\hline Imhotep & $\begin{array}{l}\text { Non-consolidated: } \\
\text { Smooth }\end{array}$ & $\begin{array}{l}\text { Geologically the most diverse region on 67P. Extremely } \\
\text { smooth, probably recently re-surfaced, yet bouldered region } \\
\text { enclosed by horizontally bedded and vertically jointed ridges. } \\
\text { There is strong evidence of mass-wasting all around the smooth } \\
\text { areas as well as the presence of conical structures and pits that } \\
\text { are possibly the result of mechanisms similar to mud volcanism. }\end{array}$ & $\begin{array}{l}\bullet \text { Conical mounds } \bullet \text { Linear fea- } \\
\text { tures in enclosed smooth de- } \\
\text { posits } \bullet \text { Field of large boulders }\end{array}$ \\
\hline Ash & $\begin{array}{l}\text { Non-consolidated: } \\
\text { Dust-covered }\end{array}$ & $\begin{array}{l}\text { Main debris-covered region of the body. Very fine deposits pos- } \\
\text { sibly a few meters thick. Similar to Ma'at region. Contains the } \\
\text { only currently identified candidate impact crater on the surface } \\
\text { of the comet. }\end{array}$ & - Candidate impact crater \\
\hline Seth & $\begin{array}{l}\text { Weakly } \\
\text { consolidated/Brittle }\end{array}$ & $\begin{array}{l}\text { Generally lacking a dust cover, yet bouldered region with ubiq- } \\
\text { uitous circular, semi-circular, and quasi-circular features that } \\
\text { display polygonal cracks in some places. Strong evidence of } \\
\text { collapse. Possibly underlies the dust in Ash. Sharp topographic } \\
\text { contact with Anubis. }\end{array}$ & $\begin{array}{l}\text { - Several circular pits } \bullet \text { Philae } \\
\text { landing site candidate "A" } \\
\text { Chain of active circular pits }\end{array}$ \\
\hline Aten & Depression & $\begin{array}{l}\text { Well-defined depression between the Imhotep, Ash, Babi and } \\
\text { Khepry regions. Not covered by debris from Ash. Possibly } \\
\text { formed through a violent short-term event. }\end{array}$ & $\begin{array}{l}\text { - High concentration of talus } \\
\text { deposits and rockfalls }\end{array}$ \\
\hline Babi & Dust-covered/Brittle & $\begin{array}{l}\text { Transitional region that grades smoothly into Ash and Seth re- } \\
\text { gions in terms of dust cover. Neighbors the Aten, Khepry and } \\
\text { Aker regions as well and displays exposures of brittle mantling } \\
\text { material at its contact with the Aten depression. }\end{array}$ & $\begin{array}{l}- \text { Brittle layered material } \bullet \\
\text { Diamond-shaped mesa display- } \\
\text { ing evidence for mass-wasting } \\
\text { and bright boulders. }\end{array}$ \\
\hline Apis & Strongly consolidated & $\begin{array}{l}\text { Flat, smooth, and lineated unit showing irregular and polygonal } \\
\text { lineations. Significant topographic change with respect to Atum } \\
\text { and Imhotep. }\end{array}$ & - Polygonal crack patterns \\
\hline Atum & Strongly consolidated & $\begin{array}{l}\text { Highly complex region. Minimal bouldering but several small } \\
\text { depressions showing some lineation. Irregular complex mounds } \\
\text { also seen. Borders the Anubis unit with ill-defined margins in } \\
\text { places. }\end{array}$ & \\
\hline Anubis & $\begin{array}{l}\text { Non-consolidated: } \\
\text { Smooth }\end{array}$ & $\begin{array}{l}\text { Smooth region very similar to Imhotep and, possibly, Hapi. } \\
\text { Some scattered boulders possibly a result of mass-wasting. } \\
\text { Smooth deposits appear faulted/folded in some regions and dis- } \\
\text { play linear features similar to those observed in Imhotep. }\end{array}$ & $\begin{array}{l}\text { - Linear features similar to } \\
\text { Imhotep suggestive of terracing } \\
\text { - Fold-like structures. }\end{array}$ \\
\hline \multicolumn{4}{|c|}{ Neck } \\
\hline Hapi & $\begin{array}{l}\text { Non-consolidated: } \\
\text { Smooth }\end{array}$ & $\begin{array}{l}\text { Narrow region connecting the head and body of the comet. } \\
\text { Currently the most active region and site of regular jet activity } \\
\text { although exact source not defined. Smooth dusty-looking mate- } \\
\text { rial along with dispersed large boulders that may have slumped } \\
\text { from the head or body regions. }\end{array}$ & - Linear field of large boulders \\
\hline \multicolumn{4}{|c|}{ Head } \\
\hline Hathor & Strongly consolidated & $\begin{array}{l}\text { A } 900 \text { m-high cliff that is opposite to the Seth region on the body } \\
\text { and rising above the Hapi region. Un-mantled and heavily lin- } \\
\text { eated in two dimensions. Shows signs of detachment. Lighting } \\
\text { makes the lineated appearance appear very uniform but other } \\
\text { viewing angles show that it is rough. }\end{array}$ & $\begin{array}{l}\text { - Alcove structure with longitu- } \\
\text { dinal terraces } \bullet \text { Rectilinear frac- } \\
\text { ture pattern on the cliffs }\end{array}$ \\
\hline Anuket & Strongly consolidated & $\begin{array}{l}\text { A complex unit that is separated from Hathor by a scarp. } \\
\text { Parallel lineations evident on Hathor are absent. It is separated } \\
\text { from Ma'at and Maftet }\end{array}$ & $\begin{array}{l}\text { - Peculiar "melted wax"-like } \\
\text { overall morphology • } 500 \mathrm{~m} \text { - } \\
\text { long linear fracture }\end{array}$ \\
\hline Ma'at & $\begin{array}{l}\text { Non-consolidated: } \\
\text { Dust-covered }\end{array}$ & $\begin{array}{l}\text { Main dust-covered region on the head. Similar to Ash. Smooth } \\
\text { deposits showing ripple-like structures, a possible sign of mobi- } \\
\text { lization. Sharp outcrops of underlying material are usually ob- } \\
\text { served. }\end{array}$ & $\begin{array}{l}\text { Striations or ripple-like } \\
\text { features around the rim of } \\
\text { Hatmehit }\end{array}$ \\
\hline Serqet & Strongly consolidated & $\begin{array}{l}\text { Small region encompassing a sharp ridge and a flat and smooth } \\
\text { plain with few boulders. }\end{array}$ & \\
\hline Nut & Depression & $\begin{array}{l}\text { Small depression between the Serqet ridge and the } \\
\text { Ma'at/Hatmehit region. Heavily bouldered. Possible result } \\
\text { of erosion of Serqet. Identifiable mostly through topography. }\end{array}$ & \\
\hline
\end{tabular}

Notes. Please refer to the figures in the main text for a visual representation of the extent and boundaries of the different regions. 
A\&A 583, A26 (2015)

Table 2. continued.

\begin{tabular}{|c|c|c|c|}
\hline Region & Region type & Description & Notable feature(s) \\
\hline \multicolumn{4}{|c|}{ Head } \\
\hline Maftet & Strongly consolidated & $\begin{array}{l}\text { Rough terrain, lineated, and bouldered with scattered patches of } \\
\text { debris neighboring the Hatmehit, Nut and Serqet regions. Many } \\
\text { small irregular depressions and pits which give the appearance } \\
\text { of lifted blocks/chunks of material and possible fluidized activ- } \\
\text { ity. }\end{array}$ & $\begin{array}{l}\text { - Pit with potentially fluidized } \\
\text { outflowing material }\end{array}$ \\
\hline Bastet & Strongly consolidated & $\begin{array}{l}\text { Rough and heavily lineated region with minimal bouldering. } \\
\text { Borders Hathor and requires anaglyph of the region to identify } \\
\text { topographic differences. Separated from Ma'at by showing only } \\
\text { limited dust cover. }\end{array}$ & - Oriented lineamints \\
\hline Hatmehit & Depression & $\begin{array}{l}\text { Well-defined depression in the head region that appears to be } \\
\text { filled with fine-grained smooth material overlain by a talus. We } \\
\text { use the topography of the edge of the depression to define the } \\
\text { region. }\end{array}$ & $\begin{array}{l}\text { - Curvilinear ridge traversing } \\
\text { the depression floor }\end{array}$ \\
\hline
\end{tabular}


Table 3. IDs for used images.

\begin{tabular}{|c|c|}
\hline Figure & Image ID \\
\hline 1 & $\begin{array}{c}\text { [a, b]: NAC_2014-08-16T10.59.16.348Z_ID30_1397549700_F22 } \\
\text { [c]: NAC_2014-08-06T02.43.16.574Z_ID30_1397549100_F22 }\end{array}$ \\
\hline 2 & $\begin{array}{l}\text { [From top to bottom]: } \\
\text { WAC_2014-09-05T02.29.12.717Z_ID30_1397549700_F18 } \\
\text { NAC_2014-08-16T13.59.14.564Z_ID30_1397549600_F22 } \\
\text { NAC_2014-08-05T23.19.14.571Z_ID30_1397549800_F22 } \\
\text { NAC_2014-08-16T13.59.14.564Z_ID30_1397549600_F22 }\end{array}$ \\
\hline 3 & $\begin{array}{c}\text { [a]: NAC_2014-08-25T12.42.54.560Z_ID30_1397549000_F22 } \\
\text { [b, c]: NAC_2014-09-16T16.24.25.334Z_ID30_1397549500_F22 } \\
\text { [d]: NAC_2014-09-05T09.35.55.539Z_ID30_1397549100_F22 }\end{array}$ \\
\hline 4 & $\begin{array}{l}\text { [a, b]: WAC_2014-09-05T06.29.13.839Z_ID30_1397549300_F18 } \\
\text { [c, d]: NAC_2014-09-16T01.48.48.337Z_ID30_1397549400_F22 }\end{array}$ \\
\hline 5 & $\begin{array}{l}\text { [a]: WAC_2014-09-10T18.35.01.774Z_ID30_1397549400_F17 } \\
\text { [b]: NAC_2014-09-10T18.34.00.345Z_ID30_1397549000_F22 } \\
\text { [c]: NAC_2014-10-20T11.38.55.625Z_ID30_1397549400_F22 } \\
\text { [d]: NAC_2014-09-20T18.34.00.391Z_ID30_1397549100_F22 }\end{array}$ \\
\hline 6 & $\begin{array}{l}\text { NAC_2014-09-10T18.34.00.345Z_ID30_1397549000_F22 } \\
\text { NAC_2014-09-10T18.34.53.880Z_ID30_1397549001_F41 }\end{array}$ \\
\hline 7 & $\begin{array}{l}\text { [a]: NAC_2014-08-05T21.43.14.596Z_ID30_1397549900_F22 } \\
\text { [b]: NAC_2014-08-22T07.42.54.574Z_ID30_1397549800_F22 } \\
\text { [c]: NAC_2014-09-11T21.48.48.342Z_ID30_1397549400_F22 }\end{array}$ \\
\hline 8 & $\begin{array}{l}\text { [a]: NAC_2014-08-05T21.43.14.596Z_ID30_1397549900_F22 } \\
\text { [b]: NAC_2014-08-22T07.42.54.574Z_ID30_1397549800_F22 } \\
\text { [c]: NAC_2014-09-11T21.48.48.342Z_ID30_1397549400_F22 }\end{array}$ \\
\hline 9 & $\begin{array}{l}\text { [a]: NAC_2014-08-26T01.42.54.658Z_ID30_1397549100_F22 } \\
\text { [b]: WAC_2014-09-14T15.58.51.437Z_ID30_1397549300_F18 } \\
\text { [c]: NAC_2014-08-26T02.42.54.581Z_ID30_1397549700_F22 } \\
\text { [d]: NAC_2014-08-22T07.42.54.574Z_ID30_1397549800_F22 }\end{array}$ \\
\hline 10 & [a]: NAC_2014-08-26T01.42.54.658Z_ID30_1397549100_F22 \\
\hline 11 & $\begin{array}{l}\text { [a]: NAC_2014-09-05T04.10.55.537Z_ID30_1397549300_F22 } \\
\text { [b, c]: NAC_2014-09-15T11.09.00.342Z_ID30_1397549400_F22 }\end{array}$ \\
\hline 12 & $\begin{array}{l}\text { [a]: WAC_2014-09-14T19.58.52.406Z_ID30_1397549300_F18 } \\
\text { [b]: NAC_2014-09-05T04.05.55.555Z_ID30_1397549600_F22 } \\
\text { and NAC_2014-09-05T04.00.55.563Z_ID30_1397549900_F22 } \\
\text { [c]: NAC_2014-09-02T12.10.22.552Z_ID30_1397549500_F22 }\end{array}$ \\
\hline 13 & $\begin{array}{l}\text { NAC_2014-09-05T04.07.24.556Z_ID30_1397549200_F71 } \\
\text { NAC_2014-09-05T04.05.55.555Z_ID30_1397549600_F22 } \\
\text { NAC_2014-09-05T04.00.55.563Z_ID30_1397549900_F22 } \\
\text { NAC_2014-09-05T04.12.24.613Z_ID30_1397549900_F71 }\end{array}$ \\
\hline 14 & $\begin{array}{l}\text { [a]: NAC_2014-09-05T02.45.55.555Z_ID30_1397549100_F22 } \\
\text { [b]: NAC_2014-09-02T23.44.22.550Z_ID30_1397549500_F22 } \\
\text { [c]: NAC_2014-09-02T12.10.22.552Z_ID30_1397549500_F22 }\end{array}$ \\
\hline 15 & $\begin{array}{l}\text { [a]: NAC_2014-09-18T00.33.01.377Z_ID30_1397549800_F22 } \\
\text { [b]: NAC_2014-09-10T11.53.43.332Z_ID30_1397549400_F22 }\end{array}$ \\
\hline 16 & $\begin{array}{l}\text { [a]: NAC_2014-08-28T12.42.54.563Z_ID30_1397549800_F22 } \\
\text { [b]: NAC_2014-09-13T08.19.59.402Z_ID30_1397549001_F41 }\end{array}$ \\
\hline 17 & $\begin{array}{l}\text { NAC_2014-08-07T20.37.34.564Z_ID30_1397549300_F22 } \\
\text { NAC_2014-08-07T20.20.34.562Z_ID30_1397549900_F22 }\end{array}$ \\
\hline 18 & $\begin{array}{l}\text { NAC_2014-09-13T08.19.08.366Z_ID30_1397549800_F22 } \\
\text { NAC_2014-09-13T08.19.59.402Z_ID30_1397549001_F41 }\end{array}$ \\
\hline 19 & $\begin{array}{l}\text { [a]: WAC_2014-09-14T20.58.50.753Z_ID30_1397549100_F18 } \\
\text { [b]: NAC_2014-08-26T06.42.56.564Z_ID30_1397549200_F22 } \\
\text { [c]: NAC_2014-09-15T21.44.07.318Z_ID30_1397549000_F22 } \\
\text { [d]: NAC_2014-10-14T20.38.32.333Z_ID30_1397549700_F22 }\end{array}$ \\
\hline 20 & $\begin{array}{l}\text { [a]: WAC_2014-10-01T23.40.21.762Z_ID30_1397549600_F17 } \\
\text { [b, c]: NAC_2014-09-09T03.58.56.392Z_ID30_1397549300_F22 }\end{array}$ \\
\hline 21 & $\begin{array}{l}\text { [a]: WAC_2014-09-29T21.26.57.775Z_ID30_1397549800_F17 } \\
\text { [b]: NAC_2014-09-20T01.05.25.335Z_ID30_1397549800_F22 }\end{array}$ \\
\hline
\end{tabular}

Notes. The first three letters show the instrument used to acquire the image (NAC or WAC). The following 15 digits display the time (in UTC) of imaging in year-month-day format followed by hour-min-sec. Finally, the last two numbers correspond to the filters used. 
Table 3. continued.

\begin{tabular}{c|c}
\hline \hline Figure & Image ID \\
\hline 22 & [a]: WAC_2014-10-19T12.22.43.758Z_ID30_1397549100_F18 \\
& [b]: NAC_2014-09-30T09.26.53.642Z_ID30_1397549100_F22 \\
& [c]: NAC_2014-10-19T12.22.15.525Z_ID30_1397549600_F22 \\
& [d]: NAC_2014-10-19T13.18.55.543Z_ID30_1397549900_F22 \\
\hline 23 & NAC_2014-09-19T00.40.54.603Z_ID30_1397549700_F22 \\
\hline 24 & [a]: WAC_2014-10-27T14.48.29.644Z_ID30_1397549100_F18 \\
& [b]: NAC_2014-09-29T17.29.17.542Z_ID30_1397549100_F22 \\
\hline 25 & WAC_2014-10-26T14.36.09.756Z_ID30_1397549500_F18 \\
\hline
\end{tabular}

\section{Appendix A: Additional figures}

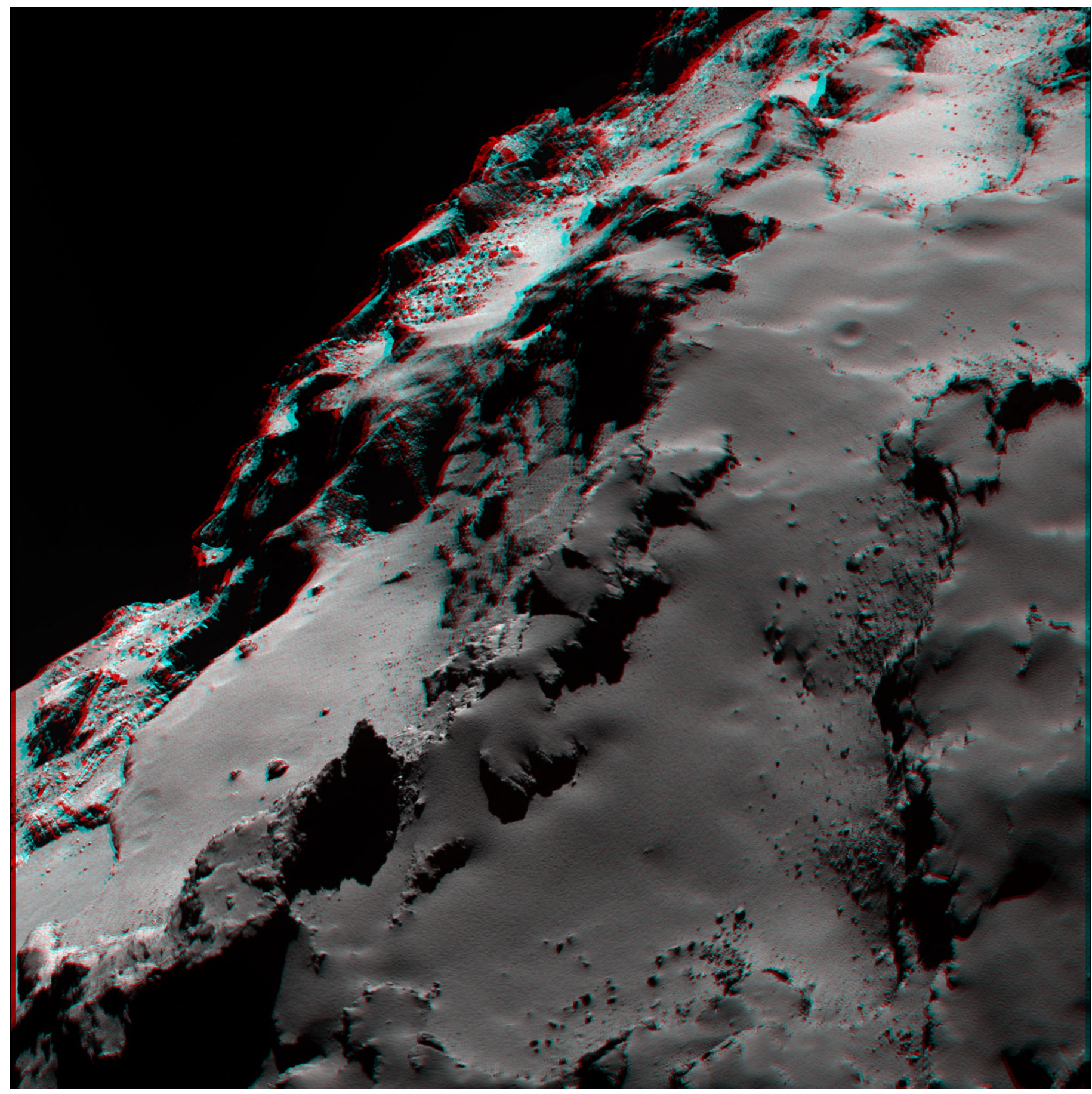

Fig. A.1. Anaglyph version of Fig. 5b in the main text. 


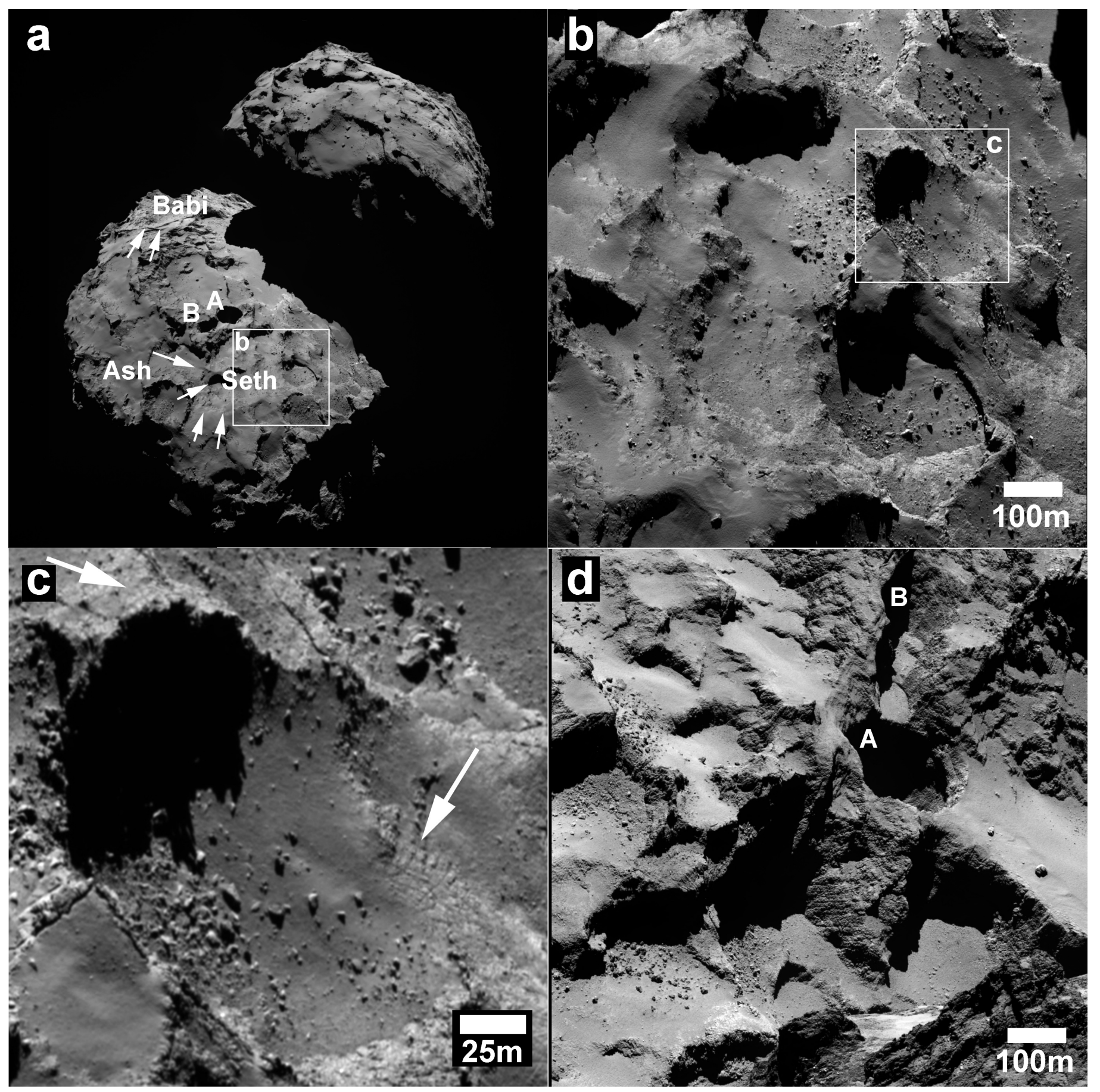

Fig. A.2. WAC image showing the Seth region in addition to Ash and Babi. Arrows point to locations of the boundaries between adjacent regions. Also visible are a couple of circular pits (A and B). b) Cropped NAC image showing prominent features of the Seth region. The material is light toned, brittle and susceptible to fracturing and collapse creating darker toned talus-like deposits as well as boulders. c) Close up of b) showing the fractures that often form polygonal patterns (arrows). d) Cropped NAC image showing one of the most remarkable circular pits (A) on the surface of the comet as well as another pit (B), which together with pit A is part of a pit chain in the Seth region. 


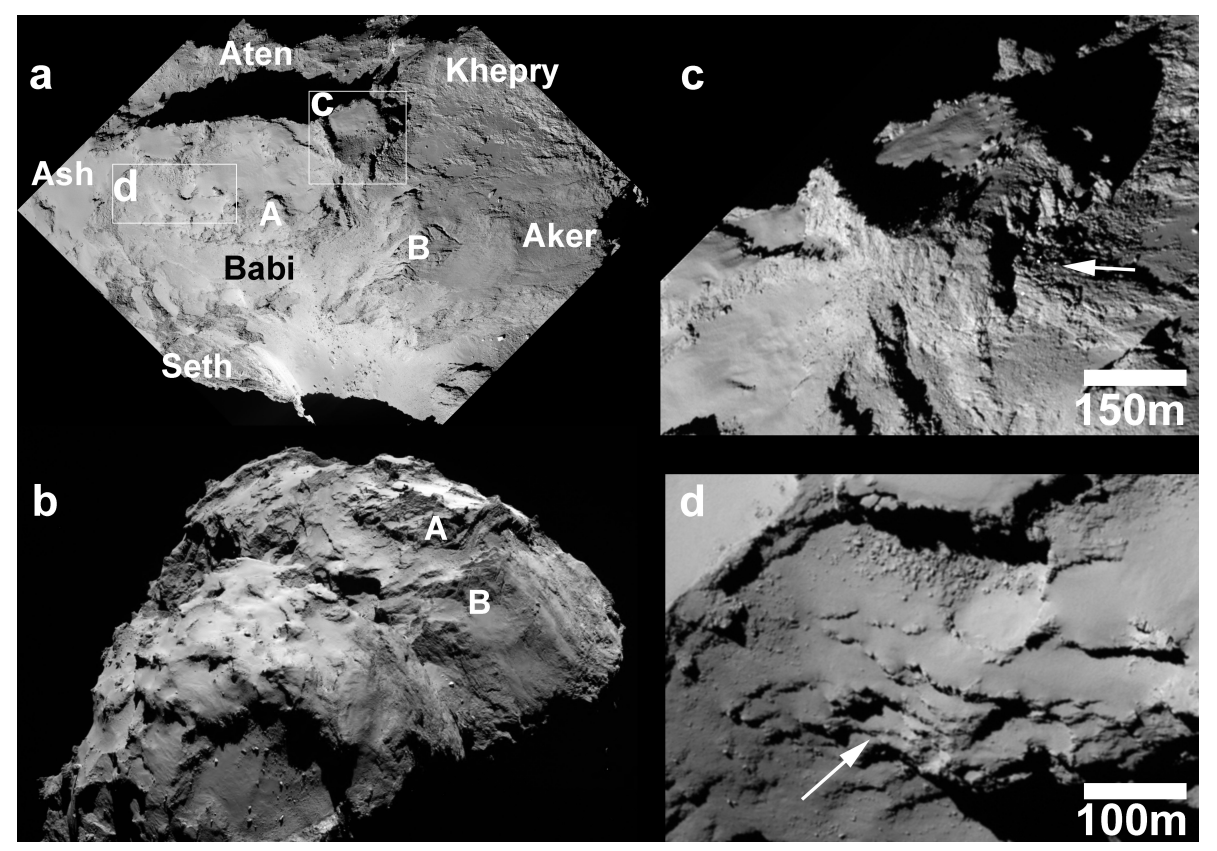

Fig. A.3. a) NAC image showing the Babi region and its surroundings. To view more accurate regional boundaries refer to other figures of the Appendix. b) Cropped WAC image showing an oblique view of the comet's body centered at Babi. Note the dark-toned material (A), which corresponds to exposed cliff material and the ridge (B) that separates Babi from Aker. Similar ridges separate Babi from Seth and Ash. c) A crop of NAC image showing the diamond-shaped mesa that separates Babi from the Khepry region. Notice the presence of bright boulders in the foot of the mesa's scarp (arrow). d) A crop of NAC image showing the layering in Babi in proximity to Aten's depression.

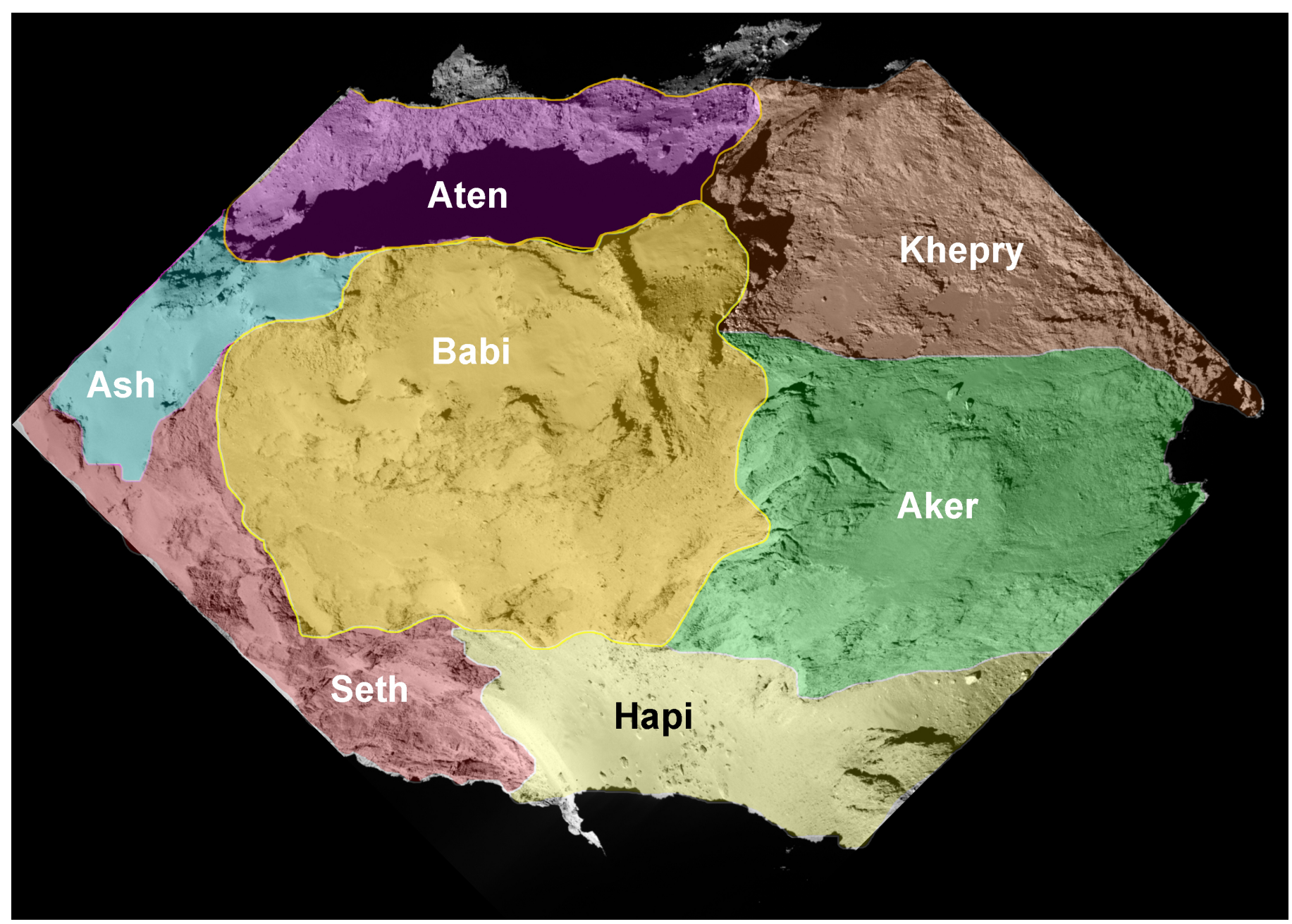

Fig. A.4. NAC image showing the regional boundaries and nomenclature superposed over Fig. 6 a. 


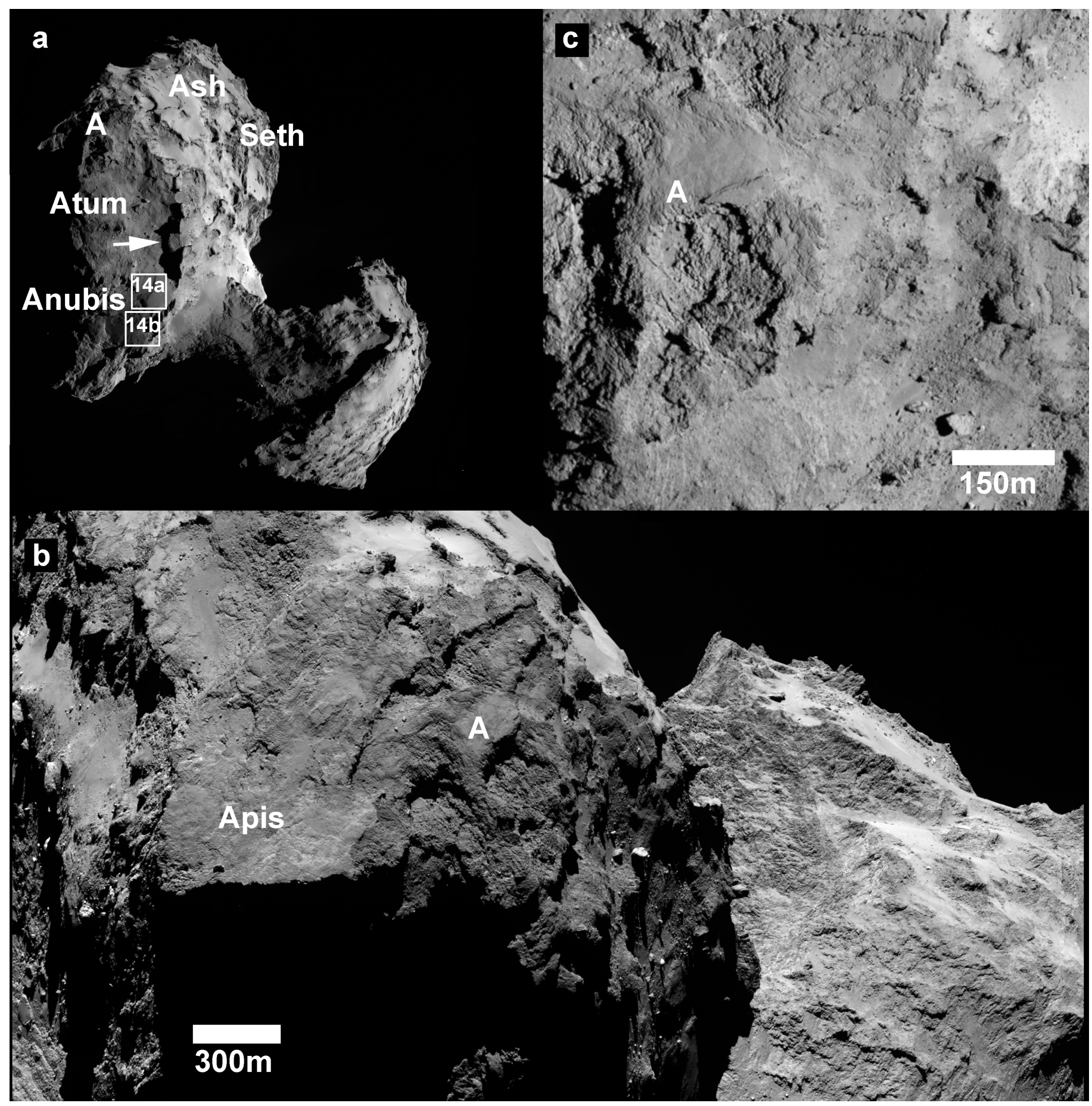

Fig. A.5. a) WAC image showing the side of the comet with Atum and Anubis regions on the body lobe. "A" marks the location of a complex depression that is highlighted in b) and c) as well. Boxes show the locations of Figs. A.7a and b while the white arrow shows the ridge separating Seth and Anubis, which is further highlighted in Fig. A.7c. b) NAC mosaic of two images showing an oblique view of the Atum region, its contact with Apis, and feature "A". Note the rough and pitted texture, and limited number of boulders. An anaglyph version of this figure is available in Fig.A.6. c) Cropped NAC image showing part of the Atum region concentrating on feature "A". 
A\&A 583, A26 (2015)

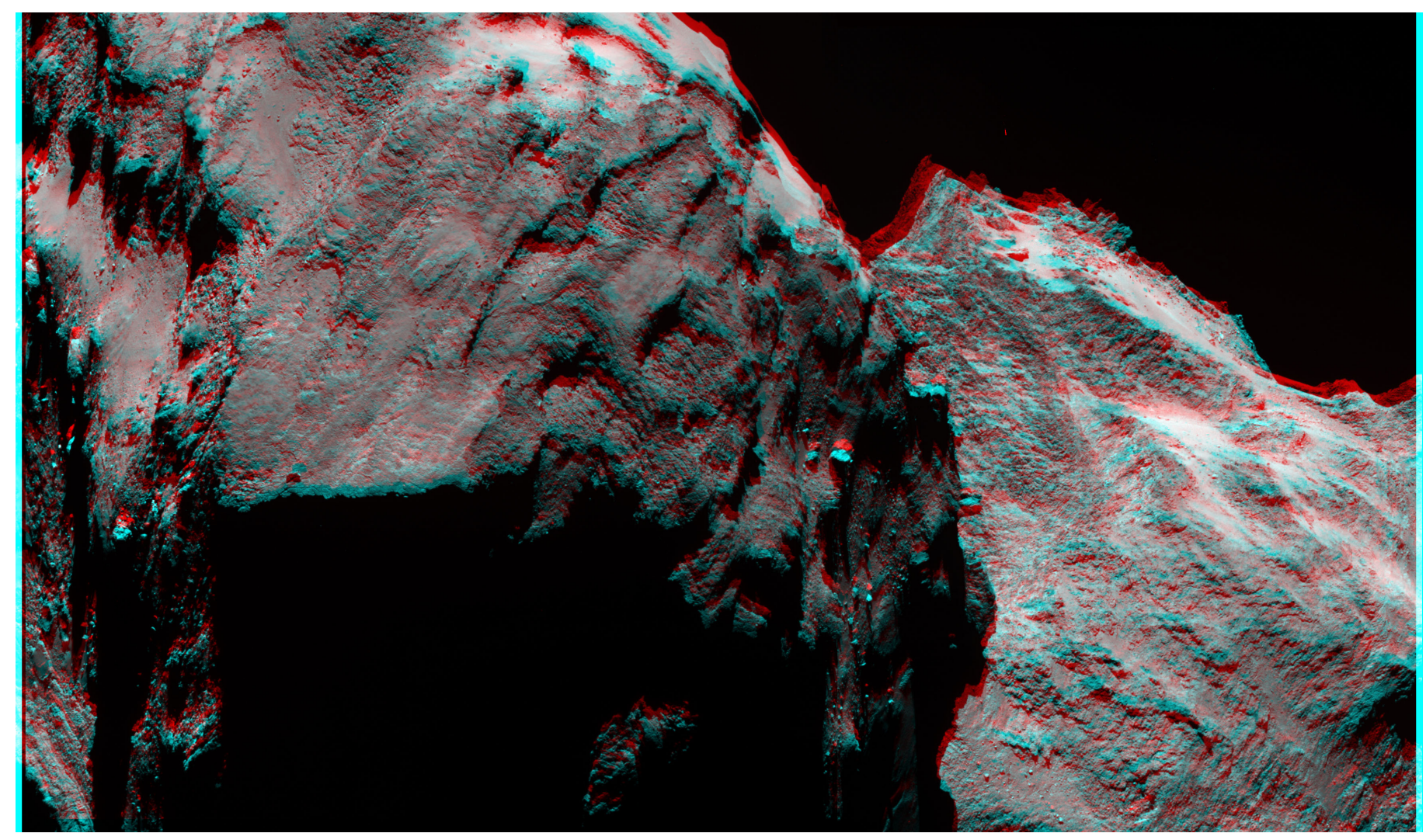

Fig. A.6. Anaglyph version of Fig. A.5b. 
M. R. El-Maarry et al.: Regional surface morphology of comet 67P

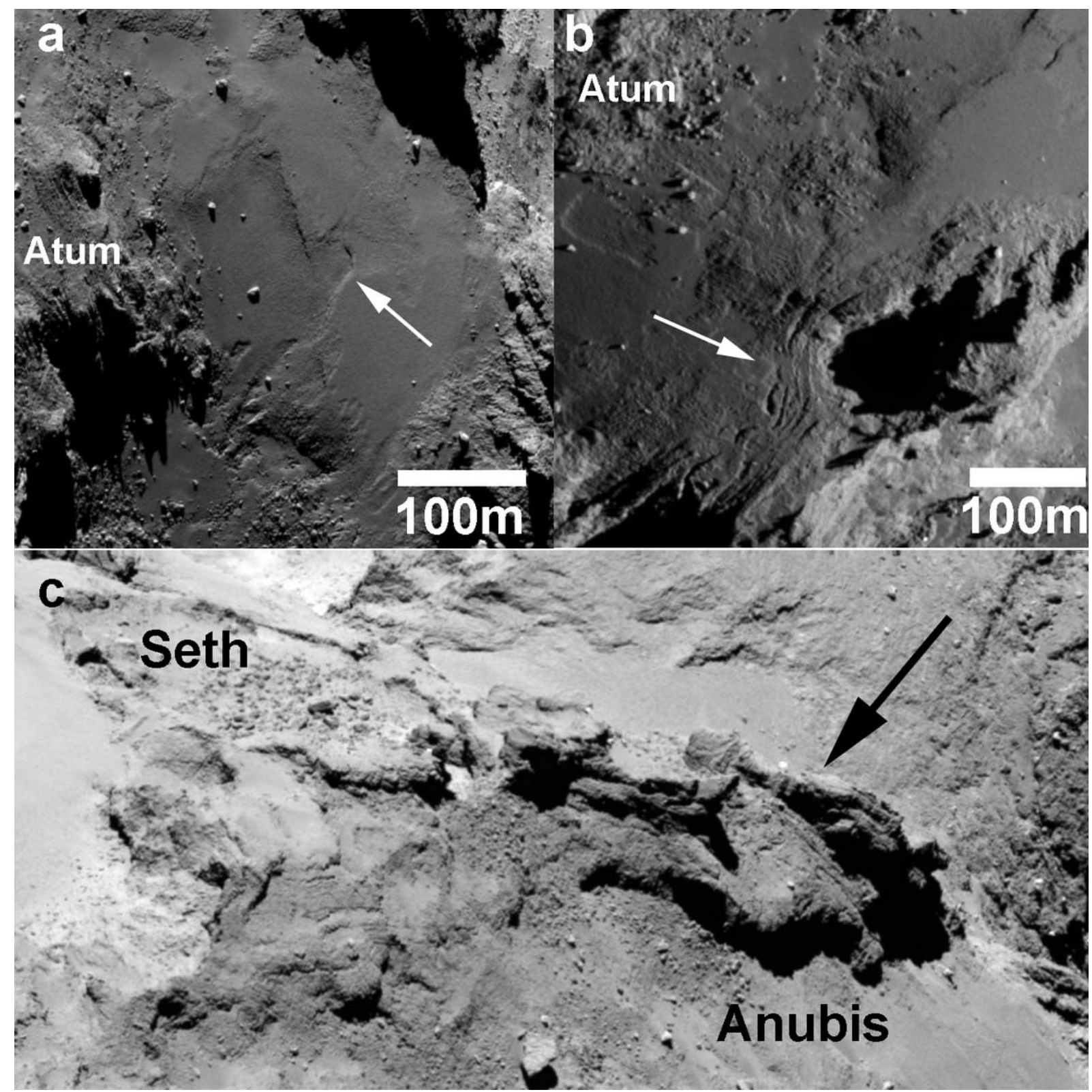

Fig. A.7. a) Crop of NAC image showing linear features in Anubis similar to Imhotep region. The Anubis region displays a considerable number of boulders, which may have originated from the Atum region. Note the smooth surface texture in comparison with the rough-textured enclosing regions of Atum and Seth. For context, refer to Fig. A.5a. b) Crop of NAC image showing possible folding in the Anubis deposits close to the boundary with Seth. c) Crop of NAC image showing the ridge separating Seth and Anubis. 
A\&A 583, A26 (2015)

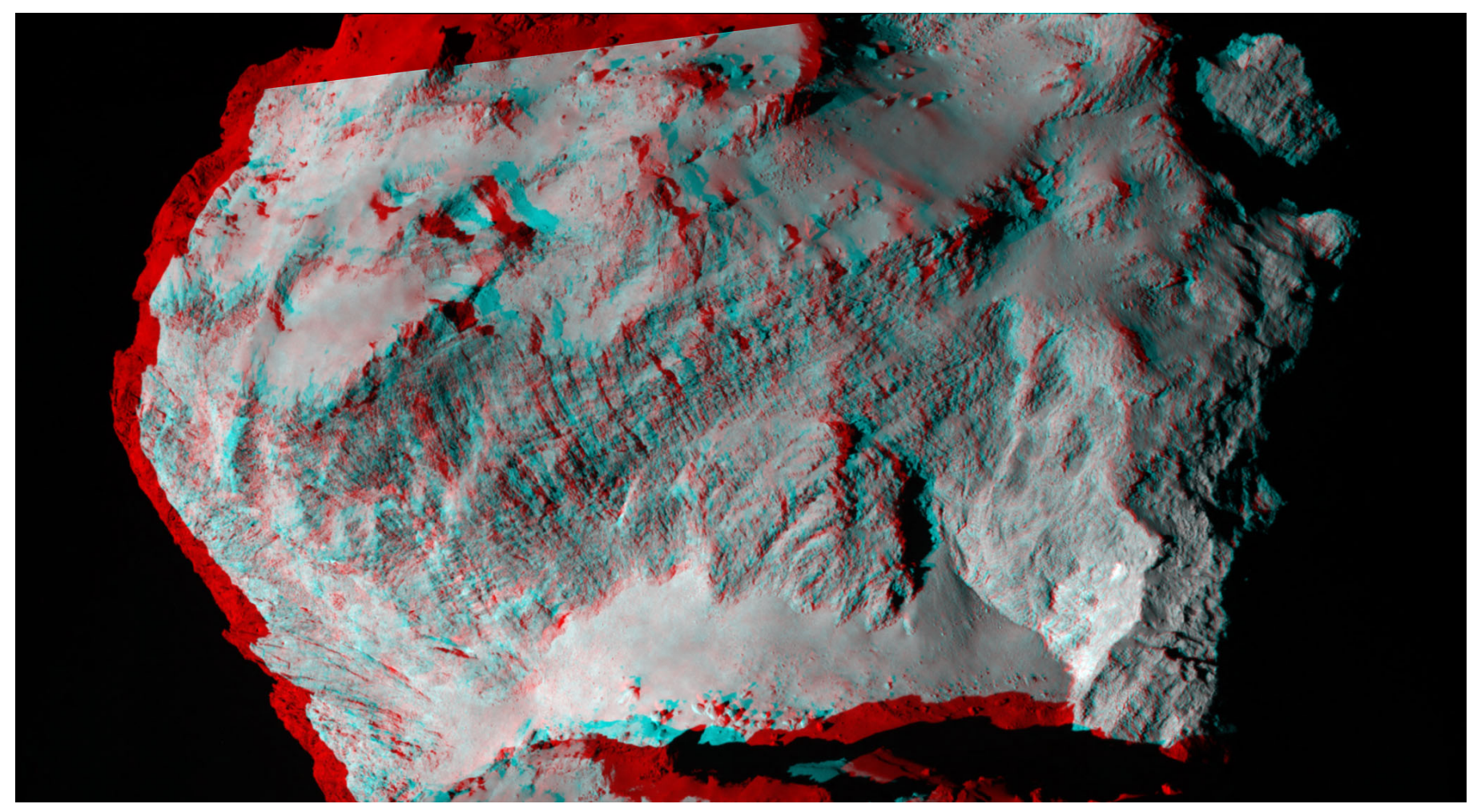

Fig. A.8. Anaglyph version of part of Fig. A.9a in the main text. 
M. R. El-Maarry et al.: Regional surface morphology of comet 67P

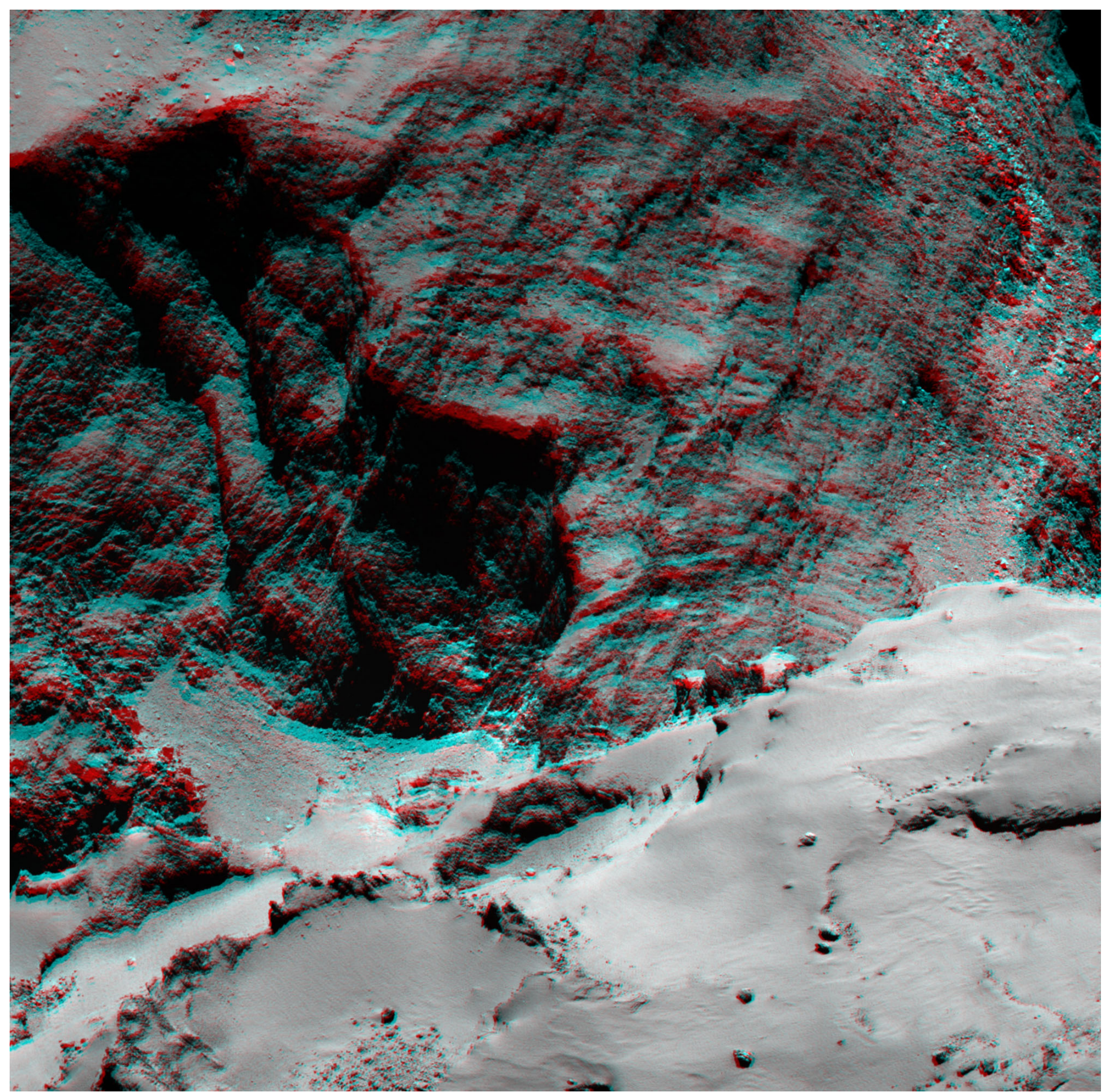

Fig. A.9. Anaglyph version of Fig. A.9b in the main text. 

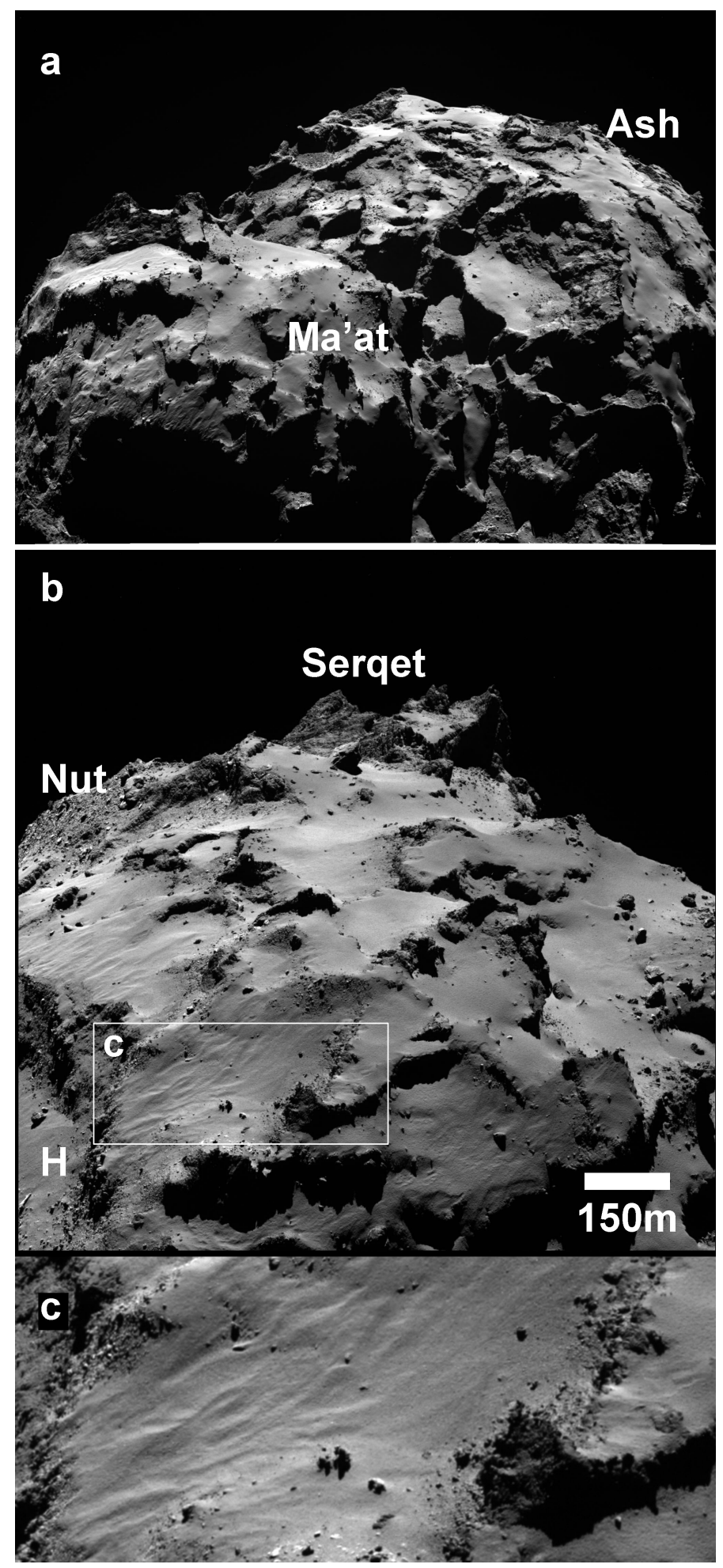

Fig. A.10. a) WAC image showing a view of the comet with the head lobe in the foreground showing the light-toned Ma'at region. Note the morphological similarity with the Ash region on the body lobe. b) NAC image showing a significant part of the Ma'at region and its surroundings. Feature $(\mathrm{H})$ corresponds to the Hatmehit region. The Ma' at region is generally smooth in texture and almost featureless except for the regions around the Hatmehit depression where the debris appears striated (inbox). c) Close-up of box in b) showing the ripple-like features in Ma'at that are common around the Hatmehit depression. The features appear to be aligned perpendicular to the depression's rim. 
M. R. El-Maarry et al.: Regional surface morphology of comet 67P

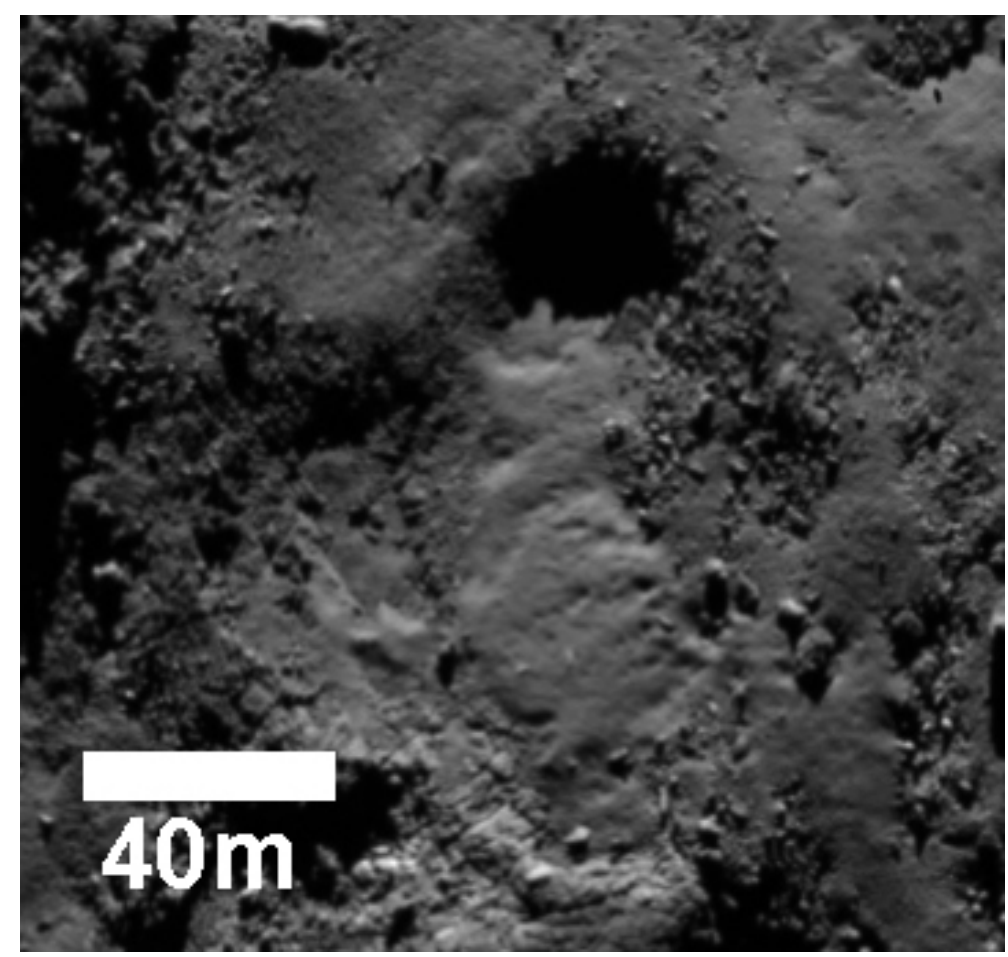

Fig. A.11. Flow-like feature and associated pit in the Maftet region. The pit is $\sim 35 \mathrm{~m}$-wide whereas the flow feature extends put for more $\sim 75 \mathrm{~m}$.

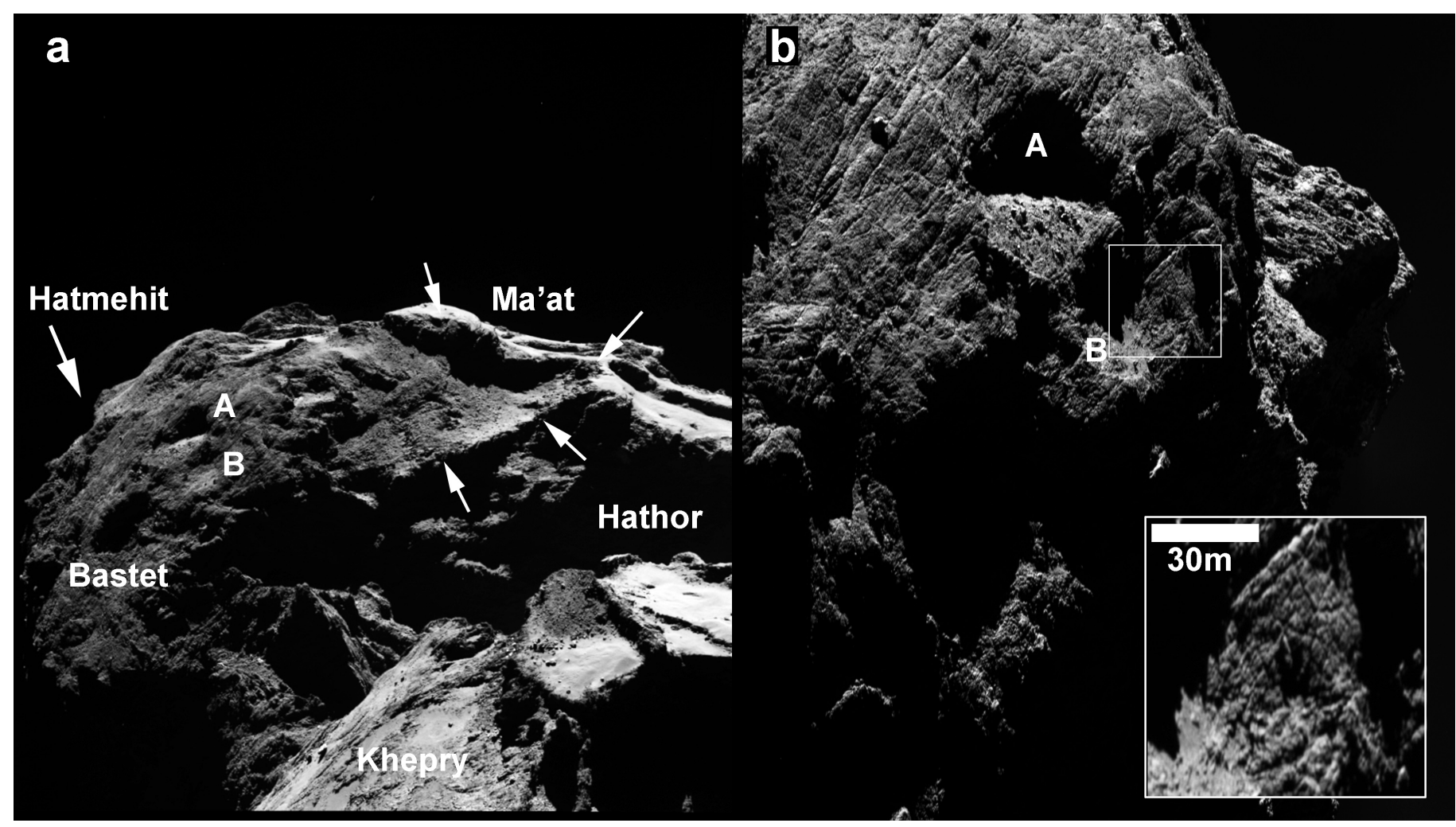

Fig. A.12. a) WAC image showing the Bastet region and its surroundings. The arrow points to the approximate location of Hatmehit behind the horizon. Note the unit's darker tone with respect to Ma'at and Khepry. (A) and (B) point to alcoves showing evidence for mass wasting. The features are further highlighted in b). Arrows point to locations of the boundaries between adjacent regions b) NAC image showing the Bastet region in higher spatial resolution. The region is characterized by pervasive fracturing that is roughly oriented parallel to the plane of Hatmehit but occasionally displays cross-cutting relationships. Fractures appear to form polygonal patterns as well in some locations (see inbox). 


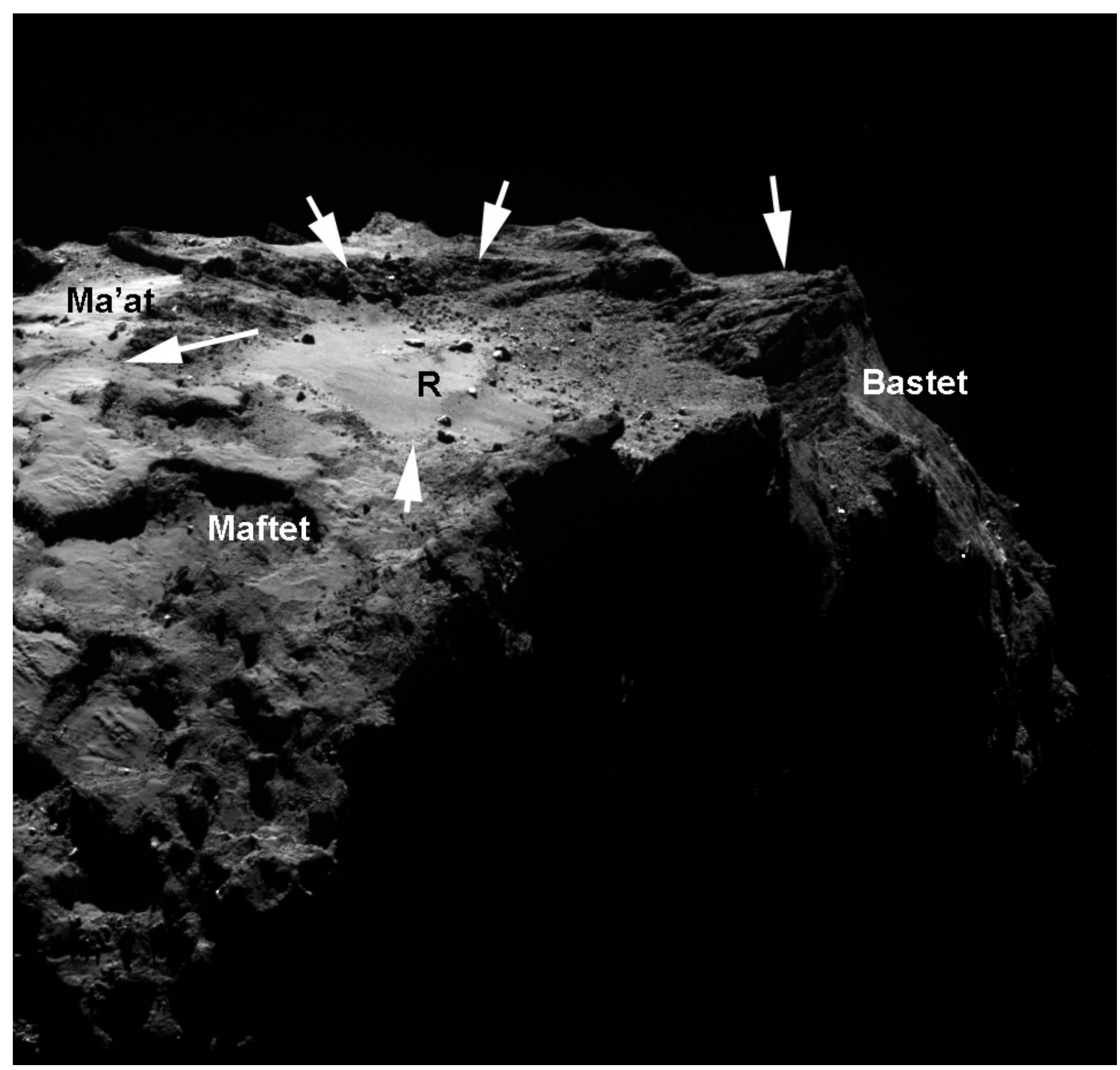

Fig. A.13. WAC image showing an oblique view of the Hatmehit depression and the regions surrounding it. Note the smooth morphology of the interior, the talus-like debris occupying parts of the depression on Bastet's side and the curvilinear ridge (feature R) that appears to traverse through the central part of the depression. Arrows highlight the depression's rim. 